\title{
Numerical simulations of wave propagation over a
} vegetated platform

\author{
Xuebin Chen ${ }^{\mathrm{a}, \mathrm{b}}$, Qin Chen ${ }^{\mathrm{b}, \mathrm{c}, *}$, Jiemin Zhan $^{\mathrm{a}}$, Don Liu ${ }^{\mathrm{d}}$ \\ ${ }^{\mathrm{a}}$ Department of Applied Mechanics and Engineering, School of Engineering, Sun Yat-sen University, \\ Guangzhou 510275, China \\ ${ }^{\mathrm{b}}$ Center for Computation and Technology, Louisiana State University, USA \\ ${ }^{\mathrm{c}}$ Department of Civil and Environmental Engineering, Louisiana State University, USA \\ ${ }^{\mathrm{d}}$ Mathematics \& Statistics and Mechanical Engineering, Louisiana Tech University, USA \\ * corresponding author: qchen@1su.edu
}

\begin{abstract}
Vegetated platforms have been constructed in recent years for the purpose of shore protection. This paper addresses some fundamental questions concerning the vegetated platform: (1) What is the difference in wave attenuation between a vegetated platform and a simple platform, and how much can vegetation increase the efficiency of reducing wave transmission? (2) Are there any differences between the effects of stems and roots on wave attenuation? (3) Does vegetation always reduce wave transmission? (4) Is it possible to develop an empirical formula for estimating the wave transmission of a vegetated platform? To answer the above questions, a numerical model solving the Navier-Stokes equations for wave propagation over a vegetated platform is established and validated by several existing laboratory experiments. A total of 244 numerical experiments based on this model have been carried out. The simulated results suggest that the platform plays a major role and the vegetation plays a supporting role in reducing wave transmission except for some special cases. Stems tend to have a larger influence than roots in reducing wave transmission with the same height. The roots always help reduce wave transmission, while the stems may increase wave transmission when the platform width is in the range of $37.5-62.5 \%$ of the incident wavelength. Based on our numerical experiments and existing laboratory data, the paper proposes a simple formula for predicting the wave transmission coefficient of a vegetated platform for engineering applications.
\end{abstract}

Keywords: vegetated platform, wave transmission, surface breakwater, vegetation drag, wave attenuation.

\section{Introduction}

Recently, the interest in wave attenuation by vegetation has increased as coastal engineers search for sustainable solutions to mitigate the impacts of climate change and natural hazards (e.g. Augustin et al., 2009; Chen and Zhao, 2012; Wu et al., 2012; Jadhav et al., 2013; Ma et al., 2013; Maza et al, 2013; Zhan et al.2014; Anderson and Smith, 2014; Hu et al., 2014; Liu et al., 2015; Zhu and Chen, 2015; Mattis et al. 2015; Maza et al., 2015). Depending on the location of vegetation in the water column and the vegetation height relative to the water depth, coastal vegetation is usually classified as 
submerged, emergent and suspended vegetation (e.g. Plew, 2010; Huai et al., 2012). Suspended vegetation is porous media and suspends downwardly from the free surface to some distance above the bottom boundary, which is a reversed, submerged vegetation. However, the influences of submerged and suspended vegetation on the flow field are completely different. The major difference between the suspended vegetation and submerged vegetation is the influence of bottom boundary layer beneath the suspended vegetation (Plew, 2010). The influence of suspended vegetation on ecosystems is complicated. In many places of the world, exotic suspended species are a severe problem, as invasive floating vegetation may completely cover the water surface, absorb oxygen and solar radiation, and block irrigation channels and hamper navigation (Huai et al., 2012). However, some suspended vegetation is a rich source of biogas, and some can be utilized to absorb organic material and heavy metals. Species with relatively rigid stems can also be utilized to reduce wind wave energy for shore protection.

Numerous laboratory experiments on wave attenuation by different submerged and emergent vegetation models have been carried out, including rigid and flexible cylindrical dowels (e.g. Augustin et al., 2009; Anderson and Smith, 2014), artificial vegetation with rigid stems (e.g. Nepf 1999; Wu et al., 2011) and flexible plants (e.g. Ghisalberti and Nepf, 2006; Blackmar et al., 2014), and real vegetation (e.g. Wu et al., 2011). However, there are few experiments that consider suspended vegetation with surface waves. Plew (2010) conducted laboratory experiments that explored aspects of the flow through suspended canopies constructed from rigid cylinders. The experiment provided details on the flow structure that may be vertically divided into a bottom boundary layer, a canopy shear layer and an internal canopy layer. Later, Huai et al. (2012) presented a simple three-layer analytical model for open channel flow through suspended rigid vegetation with various heights and showed good agreement with the experimental data in Plew (2010). Wang et al. (2014) successfully used the hydrostatic Finite Volume Coastal Ocean Model (FVCOM) to simulate the flow around suspended rigid vegetation by introducing momentum sink terms into the governing equations. So far, few researchers have used the Navier-Stokes model to simulate the flow through suspended vegetation.

Free surface breakwaters have generated a great deal of interest in the coastal and ocean engineering community for a long time. Compared with rubble-mound breakwaters, free surface breakwaters have several advantages: (1) low construction cost; (2) applicability for poor soil foundation and complex bathymetry; (3) less interference to the ecosystem; (4) easy relocation and recyclability (e.g. McCartney 1985; Dong et al., 2008). Floating plate is a classical type of free surface breakwater, which has proved useful in reducing wave transmission (e.g. Patarapanich and Cheong, 1989; Neelamani and Reddy, 1992; Neelamani and Gayathri, 2006; Dong et al., 2008; Zidan et al., 2012; Koraim, 2013; Acanal et al., 2013). To have sufficient wave height reduction by a floating plate-type breakwater, the structure is usually designed to be a long thin plate or a large box.

Recently, a new type of breakwater has attracted researchers' attention, which is composed of three parts: platform, vegetation stems and vegetation roots. It has been 
built in the Mississippi River Delta, U.S. (Fig. 1). This vegetated platform is a sustainable green infrastructure product designed for shore protection and marsh restoration in estuaries. It also provides wild life with spawning habitat and is attractive to human for recreation. The vegetated platform is similar to a suspended wetland. It operates in the upper part of the water column where most of the wave energy is concentrated, which thus reduces the wave transmission and protects the shoreline just as a surface breakwater does. Although vegetated platforms have been put into engineering practice, few studies on this type of breakwater exist to the best knowledge of the authors. This paper is aimed at filling the knowledge gap by investigating the efficiency of vegetated platform in wave energy reduction, and addressing the following questions: (1) Are there any differences between a vegetated platform and a simple platform in terms of wave attenuation? How efficient is suspended vegetation in wave attenuation? (2) Do the stems and roots of suspended vegetation have the same effects on wave transmission? (3) Does the vegetation always reduce the transmitted wave height? (4) As empirical formulas have already been used to estimate the wave transmission in the condition of a simple, non-vegetated platform, would it be possible to extend them to vegetated platforms?

Fig. 1. Vegetated platforms in Mississippi River Delta. (Photo credit: Martin Ecosystems)

Vegetated platforms can protect a shoreline from erosion by reducing the wave impact. Yet, investigation on this critical role of vegetation on the platform is scarce at present, and a means for reliably determining wave height reduction by a vegetated platform in engineering practice is not yet available. The objective of this paper is to employ the Re-Normalization Group (RNG) k- $\varepsilon$ turbulence model and the volume of fluid (VOF) method based on the Navier-Stokes solver in the computational fluid dynamics (CFD) code, FLUENT, to simulate wave propagation over a vegetated platform. This paper is organized as follows. Section 2 presents a description of the methodology used in this paper focusing on the momentum sink term. Section 3 assesses the applicability of the proposed model thoroughly by comparing the numerical results with laboratory data. In section 4, we simulate a total of 244 cases of diverse vegetated platforms with various parameters using the validated CFD model. In section 5, we propose an empirical formula for determining the wave transmission coefficient for a given vegetated platform. Finally, section 6 summarizes the findings with several conclusions.

\section{Numerical model}

In this section, the governing equations and numerical wave tank used to establish the vertically two-dimensional (2-D) numerical model for wave propagation over vegetated platforms are presented. This model is based on the CFD code FLUENT, which uses the finite volume method to solve the Navier-Stokes equations. To enhance the capability of FLUENT, user-defined functions written in C programming language have been employed to build the numerical wave tank and consider the resistance force 
induced by vegetation. In the wave tank, the reflected waves from the working zone can be eliminated by the relaxation method to make sure the wave generation is stable. Further information about the relaxation method can be found in Engsig-Karup (2006) and Afshar (2010). The model has been validated by Zhan et al. (2014) for free surface flows through submerged and emergent vegetation. Therefore, this paper is focused on its applicability to flows through suspended vegetation. For details about the VOF method and other parameter settings, the reader is referred to Zhan et al. (2014).

The paper uses the Reynolds-averaged Navier-Stokes (RANS) equations and RNG $\mathrm{k}-\varepsilon$ turbulence model to simulate the flow of an incompressible viscous fluid. Additional source terms for the drag force caused by suspended vegetation are added into the momentum equations and turbulence models. The VOF method is utilized to capture the fluctuating water surface.

\subsection{Continuity and momentum equations}

For completeness, the governing equations including the drag forces induced by vegetation are briefly described as follows.

$$
\begin{aligned}
& \frac{\partial \rho}{\partial \mathrm{t}}+\frac{\partial}{\partial x_{i}}\left(\rho u_{i}\right)=0, i=1,2 \\
& \frac{\partial}{\partial \mathrm{t}}\left(\rho u_{i}\right)+\frac{\partial}{\partial x_{j}}\left(\rho u_{i} u_{j}\right)=-\frac{\partial p}{\partial x_{i}}+\rho g_{i}+\frac{\partial}{\partial x_{j}}\left[\mu\left(\frac{\partial u_{i}}{\partial x_{j}}+\frac{\partial u_{j}}{\partial x_{i}}\right)-\rho \overline{\overline{u_{i}^{\prime} u_{j}^{\prime}}}\right]-F_{i} \\
& -\rho \overline{u_{i}^{\prime} u_{j}^{\prime}}=\mu_{t}\left(\frac{\partial u_{i}}{\partial x_{j}}+\frac{\partial u_{j}}{\partial x_{i}}\right)-\frac{2}{3} \rho k \delta_{i j}
\end{aligned}
$$

where $u_{i}$ is the velocity of the mean flow, $u$ is the fluctuating velocity component. $\rho, p$ and $g_{i}$ are the water density, pressure and gravitational acceleration, respectively. $\mu$ and $\mu_{t}$ are the molecular and turbulent viscosities respectively. $-\rho u_{i}^{\prime} u_{j}^{\prime}$ is the Reynolds stress, $\delta_{i j}$ is the Kronecker delta, $k=0.5 \overline{u_{\imath}^{\prime} u_{\jmath}^{\prime}}$ is the turbulent kinetic energy, and $F_{i}$ is the resistance force induced by the suspended vegetation.

Considering a single stem, the force $f_{i}$ is given by:

$$
f_{i}=f_{D i}+f_{I i}=0.5 \rho C_{d} b_{v} u_{i} \sqrt{u_{j} u_{j}}+\rho C_{m} b_{v} t_{v} \frac{\partial u_{i}}{\partial t}
$$

where $f_{D i}$ is the drag force, $f_{I i}$ is the inertia force, $b_{v}$ and $t_{v}$ are the width and thickness of vegetation, respectively, $C_{d}$ is the drag coefficient and $C_{m}$ is the inertia coefficient. The average force per unit volume within the vegetation zone is given by:

$$
F_{i}=N f_{i}=0.5 N \rho C_{D} b_{v} u_{i} \sqrt{u_{j} u_{j}}+N \rho C_{M} b_{v} t_{v} \frac{\partial u_{i}}{\partial t}
$$

where $N$ is the number of vegetation stems per unit area, $\mathrm{m}^{-2}$. The blockage provided by the vegetation is characterized by its fontal area per volume, and it is called the vegetation density $a=b_{v} N, \mathrm{~m}^{-1}$ (e.g. Kaimal and Finnigan, 1994; Nepf and Vivoni, 2000). The Keulegan-Carpenter (KC) number is defined as $\mathrm{KC}=u_{\mathrm{c}} T / b_{\mathrm{v}}$, where $u_{\mathrm{c}}=$ characteristic velocity acting on the vegetation, and $T=$ wave period. As the $\mathrm{KC}$ number in the paper is in the range of 55-354, which is greater than 45 , the drag force is 
dominant and the inertia force is negligible (Journée and Massie, 2001; Zhu and Chen, 2015). Note that $C_{D}$ in Eq. (5) is called the bulk drag coefficient that considers the sheltering effects of adjacent vegetation stems, and will be determined by laboratory experiments.

\section{2. Turbulence model}

The RNG $k$ - $\varepsilon$ turbulence model is employed to appropriately model the Reynolds stress, and the turbulence kinetic energy $k$ and its rate of dissipation $\varepsilon$ are obtained from the following transport equations:

$$
\begin{gathered}
\frac{\partial}{\partial \mathrm{t}}(\rho k)+\frac{\partial}{\partial x_{j}}\left(u_{j} \rho k\right)=\frac{\partial}{\partial x_{j}}\left(\alpha_{k} \mu_{e f f} \frac{\partial k}{\partial x_{j}}\right)+G_{k}+G_{b}-\rho \varepsilon-Y_{M}+C_{f k} F_{i} u_{i} \\
\frac{\partial}{\partial \mathrm{t}}(\rho \varepsilon)+\frac{\partial}{\partial x_{j}}\left(u_{j} \rho \varepsilon\right)=\frac{\partial}{\partial x_{j}}\left(\alpha_{\varepsilon} \mu_{e f f} \frac{\partial \varepsilon}{\partial x_{j}}\right)+C_{1 \varepsilon} \frac{\varepsilon}{k}\left(G_{k}+C_{1 \varepsilon} G_{b}\right)-C_{2 \varepsilon} \rho \frac{\varepsilon^{2}}{k}-R_{\varepsilon}+C_{1 \varepsilon} \frac{\varepsilon}{k} C_{f \varepsilon} F_{i} u_{i} \\
\mu_{t}=\rho C_{\mu} \frac{k^{2}}{\varepsilon}, G_{k}=\mu_{t}\left(\frac{\partial u_{i}}{\partial x_{j}}+\frac{\partial u_{j}}{\partial x_{i}}\right) \frac{\partial u_{i}}{\partial x_{j}}
\end{gathered}
$$

where $F_{i}$ is the average force per unit volume within the vegetation zone, and $u_{i}$ is the velocity of the mean flow. $C_{f k} F_{i} u_{i}$ and $C_{1 \varepsilon} C_{f \varepsilon} F_{i} u_{i} \varepsilon / k$ are source terms due to the vegetation resistance in the $k$ and $\varepsilon$ equations, respectively, which were also adopted by other researchers (e.g. Tsujimoto et al., 1991; Lopez and Garcia, 1997; Zhan et al., 2014). $G_{k}$ represents the generation of turbulent kinetic energy due to the mean velocity gradients, and $G_{b}$ is the generation of turbulent kinetic energy due to buoyancy, which is neglected as temperature gradient is not considered in the present simulation. $Y_{M}$ is the contribution of the fluctuating dilatation in compressible turbulence to the overall dissipation rate, which is also omitted as the flow is assumed incompressible. $\alpha_{k}$ and $\alpha_{\varepsilon}$ are the inverse effective Prandtl numbers, the empirical constants $C_{1 \varepsilon}=1.42$ and $C_{2 \varepsilon}=$ 1.68. $\mu_{\text {eff }}$ is the effective viscosity.

\section{Model validation}

\subsection{Wave propagation in a channel with submerged and emergent vegetation}

The laboratory data from Augustin et al. (2009) are used to test the numerical model described in the previous section. Monochromatic waves were generated in a $30.5 \mathrm{~m}$ long wave flume. The waves propagated over submerged or emergent vegetation. The vegetation field was placed approximately $13.1 \mathrm{~m}$ from the wave maker and extended $6 \mathrm{~m}$ down the length of the wave flume. Rigid vegetation was simulated by cylindrical wooden dowels with a height and a diameter of $0.3 \mathrm{~m}$ and $0.012 \mathrm{~m}$, respectively. The vegetation population density was $194 / \mathrm{m}^{2}$, i.e. $a=2.328 / \mathrm{m}$. In the case of emergent vegetation, the vegetation height immersed in the water $\left(l_{s}\right)$ is equal to the water depth $(D)$. In the case of submerged vegetation, the immersed vegetation height $\left(l_{s}\right)$ is less than the water depth $(D)$. Simulations of waves in both emergent and submerged cases were numerically carried out to compare with the laboratory data. In the emergent case, the water depth was $0.3 \mathrm{~m}$, the vegetation height was $0.3 \mathrm{~m}$, the wave period was $1.5 \mathrm{~s}$, and the wave height was $0.09 \mathrm{~m}$.. In the submerged case, the water depth was $0.4 \mathrm{~m}$, the vegetation height was $0.3 \mathrm{~m}$, the wave 
period was $1.5 \mathrm{~s}$, and the wave height was $0.12 \mathrm{~m}$. As the Boussinesq model used in Augustin et al. (2009) was an approximation of the N-S model, leading to different bulk drag coefficients, we calibrated the values of $C_{D}$ for the two cases and found they were all 1.6. In the mesh sensitivity test, two sets of grid resolution were used. One set of resolution was $d x=0.02 \mathrm{~m}$ and $d y=0.0036 \mathrm{~m}$, and the other set of resolution was $d x=$ $0.015 \mathrm{~m}$ and $d y=0.0025 \mathrm{~m}$. From the comparison of the results between these two sets of mesh resolution, we found no differences. Thus, we chose $d x=0.02 \mathrm{~m}$ and $d y=$ $0.0036 \mathrm{~m}$ as the mesh resolution in numerical simulations. The time step, $d t$, was chosen $0.002 \mathrm{~s}$.

Fig. 2. Comparison of the calculated and measured wave height reductions. (a) Emergent vegetation; (b) submerged vegetation.

The comparison between the calculated and measured wave heights over the vegetation field is presented in Fig. 2, where $C_{t}$ is the ratio of the attenuated wave height to the incident wave height. The differences between the numerical results $\left(C_{t_{s} \text { simulated }}\right)$ and measurements $\left(C_{t_{-} \text {measured }}\right)$, i.e. $\left|C_{t_{-} \text {simulated }} C_{t_{-} \text {measured }}\right|$, are $0.9 \%, 4.8 \%, 2.3 \%$ in Fig. 2(a) and 3.5\%, 1.6\%, $0.0 \%$ in Fig. 2(b), respectively. The numerical results are in good agreement with the experimental data. As expected, both the simulated and measured wave heights decreased along the vegetation field in both the emergent and submerged cases.

\subsection{Flow through suspended canopy}

The laboratory experiments of flow through suspended canopy were carried out by Plew (2010) in an open channel with suspended canopies constructed from arrays of circular cylinders. The flume was $6 \mathrm{~m}$ long by $0.6 \mathrm{~m}$ wide. Canopies were constructed from $9.54 \mathrm{~mm}$ diameter aluminum cylinders and extended over the full width and the entire working length of the flume. The velocity profiles were measured at a distance of $4 \mathrm{~m}$ from the flow inlet by using the particle tracking velocimetry (PTV). A schematic of the suspended canopy model is shown in Fig. 3. $U_{0}$ is the depth average velocity. $D$ is the total water depth in the flume, $l_{s}$ is the canopy height inundated in water and $l_{g}$ is the gap size beneath the canopy.

Fig. 3. Schematic of the suspended canopy model (modified from Plew, 2010).

In this paper, two sets of experiment runs were used to test our numerical model. One set considered different canopy densities (B12, B13, B14 and B15) and the other set considered different gap sizes (B2, B5, B9 and B13), and the main experimental parameters for each run are presented in Table 1 (see Plew, 2010 for details). As the analytical model used in Plew (2010) was an approximation of the N-S model, leading to different bulk drag coefficients, we calibrated the values of $C_{D}$ based on the laboratory data, which were treated as being spatially uniform within the canopy field. The comparison between the experimental data and numerical results is shown in Fig. 4. Good agreement is obtained, indicating the current model is applicable to flows through 
the suspended vegetation.

\section{Table 1}

Parameters for the experimental runs. $Q$ is the flow rate (data obtained from Plew 2010).

\begin{tabular}{cccccc}
\hline Run & $D(\mathrm{~mm})$ & $l_{g}(\mathrm{~mm})$ & $a(/ \mathrm{m})$ & $Q(\mathrm{~L} / \mathrm{s})$ & $C_{D}$ (calibrated $)$ \\
\hline B2 & 200 & 25 & 1.272 & 7.1 & 1.8 \\
B5 & 200 & 50 & 1.272 & 7.8 & 1.04 \\
B9 & 200 & 75 & 1.272 & 8.9 & 1.15 \\
B12 & 200 & 100 & 1.908 & 10.5 & 1.01 \\
B13 & 200 & 100 & 1.272 & 10.1 & 1.1 \\
B14 & 200 & 100 & 0.954 & 10.1 & 1.0 \\
B15 & 200 & 100 & 0.477 & 10.3 & 0.9 \\
\hline
\end{tabular}

The influences of submerged and suspended canopy on the velocity field are completely different. The major difference is that the no-slip bottom boundary constraint can significantly affect the flow below the suspended, while the water surface has almost no constraint on the velocity for flows in the submerged case. The profiles of the normalized velocity, $U / U_{0}$, and the shear stress are similar as seen in Fig. 4. Both increased from the bed and reached a maximum, and then decreased into and within the canopy and approached a constant value in the upper canopy. The maximum velocity occurred between the canopy bottom and the bed, while the maximum shear stress appeared at the interface of the suspended canopy and the water below. Both the numerical simulation and laboratory measurement show that the velocities were all positive, while shear stresses were negative near the bed and became positive as the distance from the bed becames larger. The maximum velocity always occurred between the canopy bottom and the bed regardless of how the canopy density or gap size was changed. Similarly, the maximum shear stress always appeared around the canopy and water interface regardless of the canopy density or gap size.

Fig. 4. Effects of canopy density $a$ and gap size beneath the canopy $l_{g}$ on profiles of mean velocity and turbulent shear stress. $y$ is the distance above the bed (m). (a) Effect of vegetation density $a$; (b) effect of gap size beneath the canopy $l_{g}$.

The calibrated $C_{D}$ values are listed in the last column of Table 1. In the literature, $C_{D}$ values vary greatly, ranging from a constant $C_{D}$ value (e.g. Ma et al., 2013; Zhang et al., 2013) to predictions by empirical formulae based on laboratory data of submerged and emergent vegetation (e.g. Kobayashi et al., 1993; Méndez et al., 1999; Maza et al., 2013). Because no formulae is currently available to estimate $C_{D}$ values for flows through a suspended vegetation field, we carried out a regression analysis based on our calibrated $C_{D}$ from Plew's (2010) laboratory experiments and developed a formula as follows. 
Eq. (9) shows that the drag coefficient $C_{D}$ is a function of canopy density $a$, Reynolds number $R e_{d}$ and relative gap size $l_{g} / D$. $R e_{d}=b_{v} u_{m} / v$, where $b_{v}$ is the plant diameter, $v$ is the kinematic viscosity, and $u_{m}$ is the maximum horizontal velocity at the still water level in front of the suspended canopy field. The formula indicates that $C_{D}$ slightly increases with a higher vegetation density. Huai et al. (2012) and Wang et al. (2014) also found similar relationships between the drag coefficient and suspended canopy density in studying flows through suspended rigid vegetation by a simple three-layer analytical model and FVCOM, respectively. At higher canopy densities, both flow velocity and Reynolds number in the model domain were reduced, leading to larger drag coefficients according to the relationship between $C_{D}$ and the Reynolds number for a single cylinder (Schlichting 1968). $C_{D}$ increases with the decrease of gap size $l_{g}$, which was also found in Huai et al. (2012). For a smaller gap size, the average flow velocity and Reynolds number within the canopy were reduced, and it is similar to the influence of vegetation density on $C_{D}$. $C_{D}$ is also negatively correlated with $R e_{d}$, and it is similar to what was found in submerged and emergent cases (e.g. Kobayashi et al.,1993; Méndez et al.,1999; Maza et al., 2013). This suggests that a suspended canopy could be treated as an emergent canopy when the gap size $l_{g}$ is very small compared with the water depth. Although Eq. (9) might not be accurate enough because the amount of experimental data is limited, a varying $C_{D}$ based on the formula is considered more realistic than the use of a constant $C_{D}$. Physical experiments on waves propagation through suspended vegetation are highly desirable. In the absence of such data, we utilize Eq. (9) to help answer the questions posed in the introduction section of the paper.

\section{Numerical experiments}

\subsection{Numerical model setup}

As seen in Fig. 1, the vegetated platforms were constructed in sheltered water bodies in Mississippi River Delta. Based on our field data collected in the region during storms (Chen et al., 2013; Jadhav et al., 2013), the numerical experiment setup for wave propagation over suspended vegetated platforms and the mesh distribution of the model are shown in Fig. 5. The relevant parameters in the numerical experiments were set to be within a realistic range under storm conditions: the water depth $(D)$ ranging from 1.0 to $1.8 \mathrm{~m}$, the wave length $(L)$ ranging from 4.0 to $8.0 \mathrm{~m}$, the incident wave height $\left(H_{i}\right)$ ranging from 0.1 to $0.6 \mathrm{~m}$, the platform width $(W)$ ranging from 0.5 to $10.0 \mathrm{~m}$, the vegetation density ( $a$ ) ranging from 0 to $45 / \mathrm{m}$, the root height $\left(h_{r}\right)$ ranging from 0.0 to $0.8 \mathrm{~m}$, and the effective stem height $\left(h_{s}\right)$ ranging from 0.0 to $0.4 \mathrm{~m}$. It is worth mentioning that although the actual vegetation height can be taller than $0.4 \mathrm{~m}$, we only considered the portion of the stem height (effective height) that affects the green water flow above the platform. The platform thickness $t=0.2 \mathrm{~m}$ and the vegetation stem and root diameter $b_{v}=0.006 \mathrm{~m}$. The vegetation densities of stems and roots were assumed to be the same in this study. Due to the lack of experimental data on waves over 
vegetated platforms, we used the same $C_{D}$ values for vegetation stems and roots. The transmitted wave height $\left(H_{t}\right)$ was computed from the RANS model output.

Fig. 5. Numerical model setup and the corresponding mesh distribution. (a) model setup; (b) computational mesh.

A fine computational mesh was employed for the numerical experiments: at least 120 nodes within a wavelength in the horizontal direction and 25 nodes within a wave height in the vertical direction for highly nonlinear waves. The model results are sensitive to the node number above the platform surface. To test the convergence of the model, one of the simulated cases for wave propagation over a $2 \mathrm{~m}$ long vegetated platform was tested with three different mesh resolutions (node numbers 90, 120 and 160). We found that there is virtually no difference among the results of the transmitted-wave surface elevation and vertical force acting on the platform in the three mesh resolutions. We therefore used 120 nodes on the $2 \mathrm{~m}$ long platform, i.e. 60 nodes per meter and similar resolution above the platforms in all the numerical experiments.

The numerical experiments consisted of 244 test cases with different combinations of the model parameters. The grid number in each test case was around 200,000, which has to be run on cluster computers. Most of the 244 test cases are described in the main text of the paper, and the remaining cases are listed in the appendix.

\subsection{Results and discussion}

Because all of the following test cases involve several parameters, abbreviations are used to describe a case. For example, H0.2_W1_Stem0.2Root0.2 denotes the case with the incident wave height $H_{i}=0.2 \mathrm{~m}$, the platform width $W=1 \mathrm{~m}$, the stem height $h_{s}$ $=0.2 \mathrm{~m}$, and the root height $h_{r}=0.2 \mathrm{~m}$. Similarly, H0.4_W2_Stem0.0Root0.0 means $H_{i}$ $=0.4 \mathrm{~m}, W=2 \mathrm{~m}, h_{s}=0.0 \mathrm{~m}$, and $h_{r}=0.0 \mathrm{~m}$, i.e. a simple platform without vegetation.

\subsubsection{Influence of relative platform width}

Fig. 6 shows the computed wave transmission coefficient $\left(C_{t}\right)$ varying with the relative platform width $(W / L)$ at two different incident wavelengths and water depths. It is seen that $C_{t}$ decreased to around 0.2 when $W / L$ reached 1.0. Overall, $C_{t}$ decreased with an increase in $W / L$ before reaching a low point (a local minimum in the transmission curve around $W / L=0.5$ when $H_{i}=0.4 \mathrm{~m}$ ) and increased with $W / L$ after that before reaching a high point (a local maximum around $W / L=0.75$ when $H_{i}=0.4$ $\mathrm{m})$. Because $C_{t}$ was relatively small at the first local minimum of the transmission curve, it would be a good idea to choose the corresponding $W$ as an optimum platform width. The physical experiments and theoretical results (e.g. Dick and Brebner, 1968; Hsu and Wu, 1998; Wang and Shen, 1999; Usha and Gayathri, 2005) showed that the optimum width of a simple, fixed plate was around $0.32-0.5$ of the incident wavelength. Thus it is important to know when and where such a local minimum appears in a vegetated platform.

Fig. 6. Computed wave transmission coefficient $\left(C_{t}\right)$ vs. relative platform width $(W / L)$. 
(a) $L=8 \mathrm{~m}, D=1.8 \mathrm{~m}, t=0.2 \mathrm{~m}, a=9.0 / \mathrm{m}, H_{i}=0.2-0.6 \mathrm{~m}$; (b) $L=4 \mathrm{~m}, D=1.0 \mathrm{~m}, t=$ $0.2 \mathrm{~m}, a=9.0 / \mathrm{m}, H_{i}=0.1-0.3 \mathrm{~m}$

In general, vegetation helps reduce the wave transmission over a vegetated platform, but the effect of vegetation on wave transmission decreases with an increase in platform width. Our numerical experiments showed that the vegetation was most efficient when the relative platform width $W / L$ was in the range of $0.125-0.25$, and the difference in wave transmission between a simple platform and a vegetated platform could reach $20 \%$ as seen in Fig. 6. However, vegetation didn't always play a positive role in reducing the wave transmission. The presence of vegetation could eliminate the first local minimum in the wave transmission curve for a simple platform. To understand the adverse impact of vegetation on wave transmission over a simple platform, additional test cases (H0.4_Stem0.0Root0.2, H0.4_Stem0.0Root0.8, H0.4_Stem0.2Root0.0, H0.6_Stem0.0Root0.2, H0.6_Stem0.0Root0.8, H0.6_Stem0.2Root0.0) were simulated and the results were plotted in Fig. 6(a). These results indicated that the stems contributed to the absence of the local minimum transmission for a vegetated platform, while the roots did not change the shape of the transmission curve. In other words, roots always helped reduce $C_{t}$, while stems decreased $C_{t}$ in general but increased $C_{t}$ when $W / L$ was around the optimal width ratio for a simple platform.

A surface platform divides the incident waves into two flow parts: one region above the platform (i.e. green water) and the other under the platform. The two sub-regions of the flow join together at the rear of the platform and result in the transmitted waves. To understand the mechanism for the absence of the transmission minimum in the case of a vegetated platform, we analyzed the velocities of the two regions at the rear of the platform and computed the term $\mathrm{F}(\mathrm{t})=\int \rho \mathrm{u}|\mathrm{u}| \mathrm{dy}$, which is essentially the horizontal momentum flux integrated vertically over each part of the flow. The absolute value was used to preserve the direction of the momentum flux. The time series of $\mathrm{F}(\mathrm{t})$ in three simple platform cases (H0.4_L8_W1_Stem0.0Root0.0, H0.4_L8_W4_Stem0.0Root0.0, H0.4_L8_W6_Stem0.0Root0.0) and three vegetated platform cases (H0.4_L8_W1_Stem0.2Root0.8, H0.4_L8_W4_Stem0.2Root0.8, H0.4_L8_W6_Stem0.2Root0.8) from the second subfigure in Fig. 6(a), are analyzed and the results are shown in Fig. 7. F(t)_Up and F(t)_Down denote the momentum flux above and below the platform, respectively. Fig. 7(a) shows that the F(t)_Up and $\mathrm{F}(\mathrm{t}) \_$Down were nearly in the same phase when $W=1 \mathrm{~m}$ and $6 \mathrm{~m}$, and in the opposite phase when $W=4 \mathrm{~m}$. The cancelation of the momentum fluxes in the two flow parts when $W=4$ m resulted in a smaller net momentum flux in the water column, and thus reduced the transmitted wave energy.

When the incident wave height is small and the flow is not separated into two parts (i.e. no green water), apart from the wave energy reflected by the platform, most of the wave energy is transmitted below the platform. Thus no transmission minimum appears along the $C_{t}$ vs. $W / L$ curve. The reason for the absence of a local minimum when $H_{i}=$ $0.2 \mathrm{~m}$ in Fig. 6(a) is that the wave height was not large enough to climb up the platform 
$(t=0.2 \mathrm{~m})$ and the $\mathrm{F}(\mathrm{t}) \_\mathrm{Up}$ was very small and negligible. As the wave height increased, the incident flow encountered the platform and separated into two flow parts. The upper flow part traveled slower than the lower flow part, and a small phase lag occurred in the case of $W=1 \mathrm{~m}$ in Fig. 7(a). When $W=4 \mathrm{~m}$, the phase lag increased and reached around 180 degrees. Consequently, the two flow parts collided. In the case of $W=6 \mathrm{~m}$, the phase lag increased and reached around 360 degree, and the two flow parts were in the same phase again. By the analysis above, we believe a second minimum would occur as the ratio of $W / L$ increases. However, we are only interested in the first minimum in this paper because the wave transmission was already very small before the appearance of the second minimum.

Fig. 7(b) shows the $\mathrm{F}(\mathrm{t})$ _Up and $\mathrm{F}(\mathrm{t})$ _Down of vegetated platforms with $W=1 \mathrm{~m}, 4$ $\mathrm{m}$ and $6 \mathrm{~m}$, respectively. A larger phase lag occurred behind the vegetated platform than that behind the simple platform as the vegetation stems directly reduced the green water velocity in the case of $W=1 \mathrm{~m}$. When $W=4 \mathrm{~m}$, as the stem area increased, most of the energy in the green water was dissipated by the vegetation, and $F(t)$ Up became very small. Consequently, no transmission minimum appeared. As the platform width increased, $\mathrm{F}(\mathrm{t})$ _Up almost reached zero and the velocity field under the platform was not influenced by the flow part above the platform at all. High frequency velocity oscillations are usually observed behind a plate-type floating breakwater, together with the fundamental frequency of the transmitted wave motion (Neelamani and Gayathri, 2006). Such high frequency oscillations induced by the simple platforms are shown in Fig. 7 (a). The majority of the high frequency motion disappeared when the simple platform was replaced by a vegetated platform with $W=1 \mathrm{~m}$ in Fig. 7(b). As $W$ increased, all of the high frequency oscillations disappeared, suggesting the vegetation acted as a filter.

Fig. 7. Time series of computed momentum flux with different platform width.

(a) simple platform; (b) vegetated platform.

\subsubsection{Influences of vegetation density $(a)$, root height $\left(h_{r}\right)$ and stem height $\left(h_{s}\right)$}

A detailed study on the influence of vegetation density on wave transmission is shown in Fig. 8(a). Wave transmission decreased with an increase in the vegetation density, and reached a minimum after a threshold value with a fixed root height. The minimum decreased as the root height and platform width increased. The threshold of vegetation density increased with increasing the root height, and decreased with increasing the platform width. The vegetation density had a limited effect on the wave transmission at a fixed root height and platform width. Dong et al. (2008) conducted experiments on the wave transmission of a board-net floating breakwater, which was a surface plane board ( $15 \mathrm{~cm}$ thick) with some rows of net underneath. They found that the wave transmission of two net arrangements (four rows of nets and seven rows of nets) exhibited almost no difference, which is similar to what we have found with respect to the vegetation effects. Besides revealing the existence of a minimum transmission and vegetation density threshold, the curves shown in Fig. 8(a) are also of importance for the development of an empirical formula of wave transmission 
described below. We used a wide range of vegetation density in our numerical experiments to demonstrate its effects on wave transmission, although the very high vegetation density (e.g. $a=30 / \mathrm{m}$ ) may not be in accordance with reality.

Fig. 8. Influences of vegetation density $(a)$, root height $\left(h_{r}\right)$ and stem height $\left(h_{s}\right)$ on wave transmission. (a) $a$ and $h_{r}$; (b) $h_{s}$.

The influence of stem height $\left(h_{s}\right)$ on wave transmission is shown in Fig. 8(b). Different cases with various wave conditions $\left(H_{i}=0.2-0.6 \mathrm{~m}\right)$ and platform widths ( $W=$ 1-2 m) were considered. A critical stem height was found in all cases. The wave transmission became independent of the stem height beyond the threshold, which is mainly a function of the incident wave height. If the stem height was greater than the maximum elevation of water above the platform, only the portion within the water contributed to the wave height reduction. For the largest wave height considered, the intensity of wave breaking and submergence conditions altered the shape of the curves in Fig. 8(b). Such a threshold varies as the incident wave height changes. The finding is of importance for the development of a parametric wave transmission formula as the stem height is one of the variables.

Our numerical experiments in Fig. 6 show that the vegetation was most efficient when the relative platform width $W / L$ was in the range of $0.125-0.25$. To directly illustrate the difference in the influences of stems and roots on wave transmission at relative small platform width, Table 2 lists the simulated results of 42 test cases. We use the wave reduction coefficient $\left(C_{r}=1-C_{t}\right)$ as a measure to judge the influence. The wavelength and water depth of all the cases in Table 2 were $8 \mathrm{~m}$ and $1.8 \mathrm{~m}$, respectively. A comparison between the simple platform and vegetated platform with $h_{s}=0$ and $h_{r}=$ $0.2 \mathrm{~m}$ shows that the maximum influence of the vegetation roots was $43.9 \%-41.6 \%=2.3 \%$ in the cases of H0.6_W2, indicating the roots with a small height had a little effect on the wave transmission compared with a simple platform. A comparison of the simple platform and vegetated platform with $h_{s}=0.2 \mathrm{~m}$ and $h_{r}=0.0 \mathrm{~m}$ shows the maximum influence was $49.8 \%-41.6 \%=8.2 \%$ for $\mathrm{H} 0.6 \_\mathrm{W} 2$, indicating the stems tended to have a much greater influence than the roots with the same height on wave transmission. The cases with $h_{s}=0.2 \mathrm{~m}$ and $h_{r}=0.2 \mathrm{~m}$ had a slightly larger influence than the cases with $h_{s}$ $=0.2 \mathrm{~m}$ and $h_{r}=0.0 \mathrm{~m}$, because the roots were added. When the root height increased to $0.8 \mathrm{~m}$ and the vegetation density increased to $9.0 / \mathrm{m}$, the vegetation played a more important role than the platform in wave reduction at H0.2_W1 and H0.4_W1. In this case, the root length was four times the effective stem height that affected the green water flow above the platform. Note that the actual vegetation height can be much larger than the effective stem height. The ratio of root height $\left(h_{r}\right)$ to water depth $(D)$ is one of the influencing parameters in the empirical formula for the wave transmission of vegetated platform. Overall, stems above the platform tended to be more efficient than roots with the same height below the platform in reducing wave transmission. The platform played a major role while the vegetation played a supporting role in reducing wave transmission except for some particular cases. 
Table 2

a) Comparison of simple platform and vegetated platform on wave reduction.

\begin{tabular}{ccc|cccccc}
\hline \multicolumn{3}{c|}{ Parameters } & \multicolumn{5}{|c}{ Wave reduction\%=100\% - Wave transmission\%, $C_{r}=1-C_{t}$} \\
\hline $\mathrm{h}_{\mathrm{s}}(\mathrm{m})$ & $\mathrm{h}_{\mathrm{r}}(\mathrm{m})$ & $\mathrm{a}(/ \mathrm{m})$ & $\mathrm{H} 0.2 \_\mathrm{W} 1$ & $\mathrm{H} 0.4 \_\mathrm{W} 1$ & $\mathrm{H} 0.6 \_\mathrm{W} 1$ & $\mathrm{H} 0.2 \_\mathrm{W} 2$ & $\mathrm{H} 0.4 \_\mathrm{W} 2$ & $\mathrm{H} 0.6 \_\mathrm{W} 2$ \\
0 & 0 & 3.0 & $6.3 \%$ & $12.5 \%$ & $18.5 \%$ & $27.2 \%$ & $37.2 \%$ & $41.6 \%$ \\
0 & 0.2 & 3.0 & $6.6 \%$ & $14.1 \%$ & $19.8 \%$ & $27.6 \%$ & $37.6 \%$ & $43.9 \%$ \\
0.2 & 0 & 3.0 & $10.3 \%$ & $15.9 \%$ & $22.9 \%$ & $28.0 \%$ & $40.0 \%$ & $49.8 \%$ \\
0.2 & 0.2 & 3.0 & $10.4 \%$ & $17.0 \%$ & $23.4 \%$ & $28.1 \%$ & $42.2 \%$ & $51.3 \%$ \\
0.2 & 0.8 & 3.0 & $11.1 \%$ & $18.7 \%$ & $29.0 \%$ & $29.0 \%$ & $43.3 \%$ & $53.4 \%$ \\
0.2 & 0.2 & 9.0 & $11.1 \%$ & $21.2 \%$ & $27.9 \%$ & $29.5 \%$ & $42.3 \%$ & $52.7 \%$ \\
0.2 & 0.8 & 9.0 & $15.5 \%$ & $32.3 \%$ & $35.0 \%$ & $34.0 \%$ & $45.5 \%$ & $58.6 \%$ \\
\hline
\end{tabular}

b) Wave reduction percent difference with respect to the no-vegetation case

\begin{tabular}{ccc|cccccc}
\hline \multicolumn{3}{c|}{ Parameters } & \multicolumn{5}{|c}{ Wave reduction percent difference with respect to the no-vegetation case } \\
\hline $\mathrm{h}_{\mathrm{s}}(\mathrm{m})$ & $\mathrm{h}_{\mathrm{r}}(\mathrm{m})$ & $\mathrm{a}(/ \mathrm{m})$ & $\mathrm{H} 0.2 \_\mathrm{W} 1$ & $\mathrm{H} 0.4 \_W 1$ & $\mathrm{H} 0.6 \_W 1$ & $\mathrm{H} 0.2 \_W 2$ & $\mathrm{H} 0.4 \_W 2$ & H0.6_W2 \\
0 & 0 & 3.0 & $0.0 \%$ & $0.0 \%$ & $0.0 \%$ & $0.0 \%$ & $0.0 \%$ & $0.0 \%$ \\
0 & 0.2 & 3.0 & $0.3 \%$ & $1.6 \%$ & $1.3 \%$ & $0.4 \%$ & $0.4 \%$ & $2.3 \%$ \\
0.2 & 0 & 3.0 & $4.00 \%$ & $3.40 \%$ & $4.40 \%$ & $0.80 \%$ & $2.80 \%$ & $8.20 \%$ \\
0.2 & 0.2 & 3.0 & $4.10 \%$ & $4.50 \%$ & $4.90 \%$ & $0.90 \%$ & $5.00 \%$ & $9.70 \%$ \\
0.2 & 0.8 & 3.0 & $4.80 \%$ & $6.20 \%$ & $10.50 \%$ & $1.80 \%$ & $6.10 \%$ & $11.80 \%$ \\
0.2 & 0.2 & 9.0 & $4.80 \%$ & $8.70 \%$ & $9.40 \%$ & $2.30 \%$ & $5.10 \%$ & $11.10 \%$ \\
0.2 & 0.8 & 9.0 & $9.20 \%$ & $19.80 \%$ & $16.50 \%$ & $6.80 \%$ & $8.30 \%$ & $17.00 \%$ \\
\hline
\end{tabular}

The influence of vegetation on wave transmission has been simulated by adding the drag force $F_{i}=0.5 \rho C_{D} a u_{i}\left(u_{j} u_{j}\right)^{0.5}$ into the momentum equations and the turbulence closure model in this study. The bulk drag coefficient $C_{D}$ and vegetation density $a$ are bound together in the drag force. If a predicted $C_{D}$ is equal to 1.0 , and the real $C_{D}$ equals 1.2 , this means that the vegetation density with the predicted $C_{D}$ should be 1.2 times larger than with the real $C_{D}$ in order to have the same drag force. From Fig. 8(a), we can see if the vegetation density changes, the simulated wave transmission coefficient would not change significantly for a relatively high vegetation density. In other words, the effect of any uncertainties in the bulk drag coefficient given by Eq. (9) on the wave transmission calculation would diminish when the vegetation density is relatively large, but the error remains for a small vegetation density.

\section{Empirical formula for wave transmission}

Although the CFD model solving the RANS equations is capable of simulating wave propagation over vegetated platforms, simple parametric models are still desirable for engineering applications. Compared with simple platforms, a vegetated platform has three parts that affect the wave transmission coefficient, i.e., platform, stems and roots. The contribution of each part is denoted as $C_{\text {platform }}, C_{\text {stem }}$ and $C_{\text {root }}$, respectively. For a simple platform, $C_{t}$ equals to $C_{\text {platform }}$. For a vegetated platform, $C_{t}$ is a function of $C_{\text {platform }}, C_{\text {stem }}$ and $C_{\text {root }}$. Each part is considered as a function of several non-dimensional parameters determined by the relevant quantities such as water depth 
$(D)$, wavelength $(L)$, wave height $(H)$, platform width $(W)$ and thickness $(t)$, vegetation density $(a)$ and the heights of root $\left(h_{r}\right)$ and stem $\left(h_{s}\right)$. Based on the wave transmission coefficients obtained from the 244 test cases of our numerical experiments, a multi-variable regression analysis is carried out and an empirical formula for estimating the wave transmission coefficient is developed as given in Eqs. (10-13). The wave transmission coefficient is a product of three coefficients, $C_{\text {platform }}, C_{\text {stem }}$ and $C_{\text {root }}$. To exclude unphysical predictions, when $C_{\text {platform }}>1$, we set $C_{\text {platform }}=1$; when $C_{\text {platform }}<0$, we set $C_{\text {platform }}=0$.

From Eqs. (10-13), we can calculate the wave reduction of a vegetated platform as 1- $C_{P} C_{R} C_{S}$, and the wave reduction of a simple platform as $1-C_{P}$, where $C_{P}$ is $C_{\text {platform }}$, $C_{R}$ is $C_{\text {root }}$ and $C_{S}$ is $C_{\text {stem }}$. The difference in wave reduction between a vegetated platform and a simple platform is therefore $C_{D D}=\left(1-C_{P} C_{R} C_{S}\right)-\left(1-C_{P}\right)=C_{P}-C_{P} C_{R} C_{S}$. If $C_{D D} /\left(1-C_{P}\right)<1$, the platform plays a major role and the vegetation plays a supporting role in reducing the wave transmission, and vice versa. Table 2 shows that when the wave transmission is large in the case of a relatively small platform width, the vegetation contributes more to the overall wave reduction in some particular cases. In contrast, when the wave transmission of a simple platform is small as the platform width increases, the influence of vegetation on the wave reduction decreases. A cost-effective design needs to find the optimal width of a vegetated platform.

$$
\begin{gathered}
C_{t}=C_{\text {platform }}\left(\frac{H}{L}, \frac{W}{L}, \frac{H}{D}\right) \cdot C_{\text {root }}\left(\frac{H}{D}, \frac{W}{L}, \frac{h_{r}}{D}, \frac{h_{r} b_{v} a}{D}\right) \cdot C_{\text {stem }}\left[\frac{\left(\frac{H}{2} * 1.3-\frac{t}{2}\right) h_{s} a}{t}\right] \\
C_{\text {platform }}=-2.42775\left(\frac{H}{D}\right)^{3.3034}+1.0179\left(\frac{W}{L}\right)^{-0.2217}-1.05772 *\left(\frac{H}{L}\right)^{0.11}, C_{\text {plafform }} \in[0,1] \\
C_{\text {root }}=1-f \cdot \tanh \left(5.987 * \frac{h_{r} b_{v} a}{D}\right), f=1-1.0135 * 0.5041^{\frac{H}{D}}\left(\frac{W}{L}\right)^{-0.01784} 0.4^{\frac{h_{r}}{D}} \\
C_{\text {stem }}=0.98374 \frac{\left(H / 2^{*} .3-t / 2\right) h_{s} a}{t}, h_{s} \in[0, H / 2 * 1.3-t / 2]
\end{gathered}
$$

Fig. 9 shows the comparison between the transmission coefficients simulated numerically and physically and those estimated by the simple empirical model (Eqs. 14-17). The coefficient of determination $\left(\mathrm{R}^{2}\right)$ is 0.952 and the root mean square error (RMSE) is $4.6 \%$ for all the cases. $\mathrm{R}^{2}$ is 0.933 and RMSE is $6.3 \%$ for a simple platform. It is seen that the new empirical formula gives a slightly better prediction for a vegetated platform than that of a simple platform. The main reason is that a local minimum and maximum existed in the transmission curve of Fig.7 for the simple platform, which made it more difficult for the empirical formula to give a very accurate prediction compared with a vegetated platform where the minimum and maximum were absent. In Eq. (11), the wave transmission coefficient decreased with an increase of the relative platform width $(W / L)$, indicating the formula is not able to accurately predict the existence of the local transmission minimum and maximum. The maximum error can reach about $14 \%$ when the wave height is extremely large. Nevertheless, the 
empirical formula gives quite satisfactory results for both vegetated and simple platforms.

Fig. 9. Comparison between numerically/physically simulated and estimated transmission coefficients.

From Eq. (10), the values of $C_{\text {root }}$, and $C_{\text {stem }}$ have to be in the range of 0 to 1 . To the authors' best knowledge, few formulas for $C_{\text {root }}$ and $C_{\text {stem }}$ exist in the literature. The condition that the two contributors have to satisfy is that when there is no vegetation, i.e., $a=0 / \mathrm{m}$, or $h_{r}=0 \mathrm{~m}$, or $h_{s}=0 \mathrm{~m}, C_{\text {root }}$ and $C_{\text {stem }}$ should be equal to 1 . As $h_{r} b_{v} a / D=$ $h_{r} b_{v}{ }^{2} N / D$, the dimensionless parameter $h_{r} b_{v} a / D$ represents the ratio of the root volume to the total volume, which is a percentage of the water occupied by the roots under the platform. Fig. 8(a) indicates that as the vegetation density (a) increased, the wave transmission reached a minimum at a critical vegetation density. For example, in the case of H0.6_W1_Stem0.2Root0.2, $C_{t}$ was equal to 0.815 when there was no vegetation on the platform $(a=0 / \mathrm{m})$ and 0.625 when $C_{t}$ reached a minimum at a large vegetation density. The value of $(0.815-0.625) / 0.815=0.233$ was called the maximum vegetation effect on a simple platform. The maximum vegetation effect is denoted as $f$ as shown in Eq. (12), which is a function of $H / D, W / L$ and $h_{r} / D$. As explained in the previous section, the stems will not play a role in eliminating the wave energy unless the green water phenomenon happens, which means that the incident wave height should be large enough to climb up the platform.

For a linear wave, the maximum elevation of an incident wave above the still water level is $H / 2$ and the height of the platform above the still water level is $t / 2$. Thus, the value of $(H / 2-t / 2)$ represents the maximum elevation of water above the platform. Because both wave nonlinearity and the slamming of waves on a platform can increase the maximum elevation of water, a value of $(H / 2 * 1.3-t / 2)$ is adopted to be the maximum height of water above the platform. As the vegetation density and vegetation height also affect the efficiency of stems in dissipating the wave energy, a dimensionless parameter is developed to characterize the effect of stems, which is shown in Eq. (13). Note that if the stem height is larger than the maximum height of water above the platform, the portion of the stems, which is higher than $(H / 2 * 1.3-t / 2)$, will not play a role. Hence, if $h_{s}>H / 2 * 1.3-t / 2$, then $h_{s}=H / 2 * 1.3-t / 2$.

Our proposed formula gives a reasonable relationship between $C_{t}$ and $H / L, W / L$, $H / D$, and predicts the $C_{t}$ very well in the 244 test cases. Can the formula be utilized to predict $C_{t}$ in existing laboratory experiments in the literature? Fig. 9 shows the predicted $C_{t}$ in 49 cases versus the measured $C_{t}$ in Patarapanich and Cheong (1989), Neelamani and Reddy (1992), Neelamani and Gayathri (2006) and Koraim (2013). The submergence of the surface platform was slightly different in different experiments. Because the thickness of the surface platform is small compared with the water depth, it is reasonable to put these data together for comparison. As no vegetation was used in those experiments, $C_{\text {root }}$, and $C_{\text {stem }}$ are both equal to 1 . Overall, our formula predicts the measured $C_{t}$ fairly well, especially in the cases of Neelamani and Reddy (1992), Neelamani and Gayathri (2006), and Koraim (2013), except for some of the cases in 
Neelamani and Reddy (1992). The proposed empirical formula is based on $244 C_{t}$ values in the range of 0.148 to 0.937 . Because the $C_{t}$ values in Neelamani and Reddy (1992) are all below 0.1, which are out of the range of 0.148 to 0.937 , some of their results are not accurately predicted by the new formula. Therefore, caution needs to be taken when applying the proposed empirical formula to the case of a very small $C_{t}$ value. For more details of the laboratory experiments on simple-plate platforms, the reader is referred to Patarapanich and Cheong (1989), Neelamani and Reddy (1992), Neelamani and Gayathri (2006), and Koraim (2013).

\section{Conclusions}

A numerical model for wave propagation over a vegetated platform is established using the Navier-Stokes (NS) equations with the volume of fluid (VOF) method and RNG $\mathrm{k}-\varepsilon$ turbulence closure. The model has been validated by laboratory experiments on monochromatic wave propagation over submerged and emergent vegetation fields as well as unidirectional flows through suspended canopies. A total of 244 numerical experiments using this validated model have been carried out and several findings were obtained. A new formula for predicting the wave transmission coefficient of a surface vegetated platform is developed based on the numerical experiments and existing laboratory data.

In general, the vegetation helps reduce the wave transmission. The vegetation is most efficient when the relative platform width, $W / L$, is in the range of $0.125-0.25$, and the influence of vegetation on wave transmission decreases with the increase of platform width. Stems tend to be more efficient than roots in reducing wave transmission with the same height. The platform plays a major role and the vegetation plays a supporting role in reducing wave transmission especially in the case of a large platform width. In some particular cases when the root height and vegetation density are large, and the relative platform width is small, the vegetation and platform are equally important. In other words, use of vegetation can reduce the width of a plate-type breakwater and reduce the cost in engineering application.

It has been reported in the literature that there exists a low point (local minimum) in the wave transmission coefficient curve as a function of the relative platform width. The low point appears when the wave height is large enough to enable the wave to climb up the simple platform, or to cause the green water phenomenon. The wave transmission coefficient reaches a minimum when the width of a non-vegetated platform is $0.375-0.625$ times the incident wavelength. The relative platform width for the minimum wave transmission is close to 0.375 when the incident wave height is small and close to 0.625 when the incident wave height is large. The vegetation on a suspended platform, however, acts as a sponge to reduce the green water flow, filters the high frequency oscillations in the flow velocity, and dissipates the flow energy. The vegetation stems can eliminate the low point of wave transmission, while the roots do not change the shape of the transmission curve. The roots always help reduce $C_{t}$, while stems can increase $C_{t}$ when the platform width is around 37.5 62.5\% of the wavelength in comparison with the case of a non-vegetated, simple platform.

The vegetation density has a limited effect on wave transmission when the density 
reaches a threshold value. Such a value increases with an increase in root height, and decreases with an increase in platform width. Wave transmission beyond the density threshold decreases as the root height and platform width increase.

All the findings in the paper are limited to regular waves. Numerical simulations of irregular waves over suspended vegetation will be conducted in the next step. To have a better prediction of the bulk drag coefficient for suspended vegetation, physical experiments on waves through vegetated platforms are highly desirable for model validation.

\section{Acknowledgements}

Support for the study was provided in part by the National Science Foundation (NSF Grants DMS-1115527, DMS-1115546, and CCF-1539567). The first author gratefully acknowledges the financial support from the China Scholarship Council and assistance provided by fellow students at LSU. High-performance computing resources were provided by Louisiana State University.

\section{Appendix. Results of remaining cases}

In the paper, a total of 244 cases are calculated to simulate wave propagation over vegetated platform. As not all of the cases are presented in the main text, the remaining cases are listed in Table 3.

Table 3 Input conditions and results of the remaining cases.

\begin{tabular}{cccccccc}
\hline$D(\mathrm{~m})$ & $H_{i}(\mathrm{~m})$ & $L(\mathrm{~m})$ & $W(\mathrm{~m})$ & $h_{s}(\mathrm{~m})$ & $h_{r}(\mathrm{~m})$ & $\mathrm{a}\left(\mathrm{m}^{-1}\right)$ & $C_{t}$ \\
\hline 1.8 & 0.2 & 8 & 1 & 0.2 & 0.2 & 3 & 0.896 \\
1.8 & 0.2 & 8 & 1 & 0.2 & 0.2 & 9 & 0.889 \\
1.8 & 0.2 & 8 & 1 & 0.2 & 0.2 & 18 & 0.865 \\
1.8 & 0.2 & 8 & 1 & 0.2 & 0.2 & 24 & 0.856 \\
1.8 & 0.2 & 8 & 1 & 0.2 & 0.2 & 30 & 0.85
\end{tabular}




\begin{tabular}{|c|c|c|c|c|c|c|c|}
\hline 1.8 & 0.2 & 8 & 1 & 0.2 & 0.8 & 3 & 0.889 \\
\hline 1.8 & 0.2 & 8 & 1 & 0.2 & 0.8 & 9 & 0.845 \\
\hline 1.8 & 0.2 & 8 & 1 & 0.2 & 0.8 & 18 & 0.782 \\
\hline 1.8 & 0.2 & 8 & 1 & 0.2 & 0.8 & 24 & 0.743 \\
\hline 1.8 & 0.2 & 8 & 1 & 0.2 & 0.8 & 30 & 0.715 \\
\hline 1.8 & 0.2 & 8 & 2 & 0.2 & 0.2 & 3 & 0.719 \\
\hline 1.8 & 0.2 & 8 & 2 & 0.2 & 0.2 & 9 & 0.705 \\
\hline 1.8 & 0.2 & 8 & 2 & 0.2 & 0.2 & 18 & 0.673 \\
\hline 1.8 & 0.2 & 8 & 2 & 0.2 & 0.2 & 24 & 0.662 \\
\hline 1.8 & 0.2 & 8 & 2 & 0.2 & 0.2 & 30 & 0.657 \\
\hline 1.8 & 0.2 & 8 & 2 & 0.2 & 0.8 & 3 & 0.71 \\
\hline 1.8 & 0.2 & 8 & 2 & 0.2 & 0.8 & 9 & 0.66 \\
\hline 1.8 & 0.2 & 8 & 2 & 0.2 & 0.8 & 18 & 0.604 \\
\hline 1.8 & 0.2 & 8 & 2 & 0.2 & 0.8 & 24 & 0.583 \\
\hline 1.8 & 0.2 & 8 & 2 & 0.2 & 0.8 & 30 & 0.558 \\
\hline 1.8 & 0.4 & 8 & 1 & 0.2 & 0.2 & 3 & 0.83 \\
\hline 1.8 & 0.4 & 8 & 1 & 0.2 & 0.2 & 6 & 0.802 \\
\hline 1.8 & 0.4 & 8 & 1 & 0.2 & 0.2 & 9 & 0.788 \\
\hline 1.8 & 0.4 & 8 & 1 & 0.2 & 0.2 & 18 & 0.748 \\
\hline 1.8 & 0.4 & 8 & 1 & 0.2 & 0.2 & 30 & 0.714 \\
\hline 1.8 & 0.4 & 8 & 1 & 0.2 & 0.8 & 3 & 0.813 \\
\hline 1.8 & 0.4 & 8 & 1 & 0.2 & 0.8 & 6 & 0.761 \\
\hline 1.8 & 0.4 & 8 & 1 & 0.2 & 0.8 & 9 & 0.677 \\
\hline 1.8 & 0.4 & 8 & 1 & 0.2 & 0.8 & 18 & 0.63 \\
\hline 1.8 & 0.4 & 8 & 1 & 0.2 & 0.8 & 30 & 0.58 \\
\hline 1.8 & 0.4 & 8 & 2 & 0.2 & 0.2 & 3 & 0.594 \\
\hline 1.8 & 0.4 & 8 & 2 & 0.2 & 0.2 & 6 & 0.59 \\
\hline 1.8 & 0.4 & 8 & 2 & 0.2 & 0.2 & 9 & 0.577 \\
\hline 1.8 & 0.4 & 8 & 2 & 0.2 & 0.2 & 18 & 0.567 \\
\hline 1.8 & 0.4 & 8 & 2 & 0.2 & 0.2 & 30 & 0.561 \\
\hline 1.8 & 0.4 & 8 & 2 & 0.2 & 0.8 & 3 & 0.584 \\
\hline 1.8 & 0.4 & 8 & 2 & 0.2 & 0.8 & 6 & 0.575 \\
\hline 1.8 & 0.4 & 8 & 2 & 0.2 & 0.8 & 9 & 0.545 \\
\hline 1.8 & 0.4 & 8 & 2 & 0.2 & 0.8 & 18 & 0.52 \\
\hline 1.8 & 0.4 & 8 & 2 & 0.2 & 0.8 & 30 & 0.468 \\
\hline
\end{tabular}

\section{References}

Acanal, L., Loukogeorgaki, E., Yagci, O., Kirca, V.O., Akgül, A., 2013. Performance of an inclined thin plate in wave attenuation. J. Coast Res. 141-146. Afshar, M.A., 2010. Numerical Wave Generation in OpenFOAM. Master's thesis. Department of Shipping and Marine technology, Chalmers University of Technology.

Anderson, M.E., Smith, J.M., 2014. Wave attenuation by flexible, idealized salt 
marsh vegetation. Coast. Eng. 83, 82-92.

Augustin, L.N., Irish, J.L., Lynett, P., 2009. Laboratory and numerical studies of wave damping by emergent and near-emergent wetland vegetation. Coast. Eng. 56(3), 332-340.

Blackmar, P.J., Cox, D.T., Wu, W.C., 2014. Laboratory observations and numerical simulations of wave height attenuation in heterogeneous vegetation. J. Waterw. Port Coast. Ocean Eng. 140(1), 56-65.

Chen, Q., Zhao, H., 2012. Theoretical models for wave energy dissipation caused by vegetation. J. Eng. Mech. 138(2), 221-229.

Chen, Q., Ozeren, Y., Zhang, G., Wren, D., Wu, W., Jadhav, R., Parker, K., Pant, H., 2013. Laboratory and field investigations of marsh edge erosion. Sediment Transport: Monitoring, Modeling and Management, A. Khan and W. Wu, (ed.), Nova Science Publishers. ISBN-13: 9781626186835, 311-337.

Dick, T.M., Brebner, A., 1968. Solid and permeable submerged breakwaters. Coastal Engineering Proceedings, 1(11).

Dong, G.H., Zheng, Y.N., Li, Y.C., Teng, B., Guan, C.T., Lin, D.F., 2008. Experiments on wave transmission coefficients of floating breakwaters. Ocean Eng. 35(8), 931-938.

Engsig-Karup A. Unstructured nodal DG-FEM solution of high-order Boussinesq-type equations. $\mathrm{PhD}$ Thesis, Technical University of Denmark, August 2006.

Ghisalberti, M., Nepf, H., 2006. The structure of the shear layer in flows over rigid and flexible canopies. Environ. Fluid Mech. 6(3), 277-301.

Hsu, H.H., Wu, Y.C., 1998. Scattering of water wave by a submerged horizontal plate and a submerged permeable breakwater. Ocean Eng. 26(4), 325-341.

Huai, W., Hu, Y., Zeng, Y., Han, J., 2012. Velocity distribution for open channel flows with suspended vegetation. Ad. Water Resour. 49, 56-61.

Hu, Z., Suzuki, T., Zitman, T., Uittewaal, W., Stive, M., 2014. Laboratory study on wave dissipation by vegetation in combined current-wave flow. Coast. Eng. 88, 131-142.

Jadhav, R.S., Chen, Q., Smith, J.M., 2013. Spectral distribution of wave energy dissipation by salt marsh vegetation. Coast. Eng. 77, 99-107.

Journée, J.M.J., Massie, W.W., 2001. Offshore hydromechanics. 1st Ed., Delft Univ. of Technology, Delft, Netherlands.

Kaimal, J.C., Finnigan, J.J., 1994. Atmospheric boundary layer flows: their structure and measurement.

Kobayashi, N., Raichle, A.W., Asano, T., 1993. Wave attenuation by vegetation. J. Waterw. Port Coast. Ocean Eng. 119(1), 30-48.

Koraim, A.S., 2013. Hydrodynamic efficiency of suspended horizontal rows of half pipes used as a new type breakwater. Ocean Eng. 64, 1-22.

Koutandos, E., Prinos, P., 2005. Design formulae for wave transmission behind floating breakwaters, IAHR XXXI Congress, Seoul. Korea, 4081-4089.

Liu, P.L.F., Chang, C.W., Mei, C.C., Lomonaco, P., Martin, F. L., Maza, M., 2015. Periodic water waves through an aquatic forest. Coast. Eng. 96, 100-117. 
Lopez, F., Garcia, M., 1997. Open-Channel Flow Through Simulated Vegetation: Turbulence Modeling and Sediment Transport. ILLINOIS UNIV AT URBANA DEPT OF CIVIL ENGINEERING.

Ma, G., Kirby, J.T., Su, S.F., Figlus, J., Shi, F., 2013. Numerical study of turbulence and wave damping induced by vegetation canopies. Coast. Eng. 80, 68-78.

Mattis, S.A., Dawson, C.N., Kees, C.E., Farthing, M.W., 2015. An immersed structure approach for fluid-vegetation interaction. Ad. Water Resour. 80, 1-16.

Maza, M., Lara, J.L., Losada, I.J., 2013. A coupled model of submerged vegetation under oscillatory flow using Navier-Stokes equations. Coast. Eng. 80, 16-34.

Maza, M., Lara, J.L., Losada, I.J., 2015. Tsunami wave interaction with mangrove forests: A 3-D numerical approach. Coast. Eng. 98, 33-54.

McCartney, B.L., 1985. Floating breakwater design. J. Waterw. Port Coast. Ocean Eng. 111(2), 304-318.

Méndez, F.J., Losada, I.J., Losada, M.A., 1999. Hydrodynamics induced by wind waves in a vegetation field. J. Geophys. Re. 104(C8), 18383-18396.

Neelamani, S., Gayathri, T., 2006. Wave interaction with twin plate wave barrier. Ocean Eng. 33(3), 495-516.

Neelamani, S., Reddy, M.S., 1992. Wave transmission and reflection characteristics of a rigid surface and submerged horizontal plate. Ocean Eng. 19(4), 327-341.

Nepf, H.M., 1999. Drag, turbulence, and diffusion in flow through emergent vegetation. Water Resour. Res. 35(2), 479-489.

Nepf, H.M., Vivoni, E. R., 2000. Flow structure in depth-limited, vegetated flow. J. Geophys. Re. 105(C12), 28547-28557.

Nepf, H.M., 2012. Flow and transport in regions with aquatic vegetation. Annu. Rev. Fluid Mech. 44, 123-142.

Patarapanich, M., Cheong, H.F., 1989. Reflection and transmission characteristics of regular and random waves from a submerged horizontal plate. Coast. Eng. 13(2), 161-182.

Plew, D.R., 2010. Depth-averaged drag coefficient for modeling flow through suspended canopies. J. Hydraul. Eng. 137(2), 234-247.

Schlichting, H. Boundary layer theory, 1968. New York, 612.

Teh, H.M., 2013. Hydraulic performance of free surface breakwaters: A review. Sains Malaysiana, 42(9), 1301-1310.

Tsujimoto, T., Kitamura, T., Okada, T., 1991. Turbulent structure of flow over rigid vegetation-covered bed in open channels. KHL progressive report, 1.

Usha, R., Gayathri, T., 2005. Wave motion over a twin-plate breakwater. Ocean Eng. 32(8), 1054-1072.

Wang, K.H., Shen, Q., 1999. Wave motion over a group of submerged horizontal plates. Int. J. Eng. Sci. 37(6), 703-715.

Wang, T., Khangaonkar, T., Long, W., Gill, G., 2014. Development of a kelp-type structure module in a coastal ocean model to assess the hydrodynamic impact of seawater uranium extraction technology. J. Mar. Sci. Eng. 2(1), 81-92.

Wu, W., Ozeren, Y., Wren, D., Chen, Q., Zhang, G., Holland, Ding, Y., Kuiry, S.N., Zhang, M., Jadhav, R., Chatagnier, J., Chen, Y., Gordji, L., 2011. Phase I Report 
for SERRI Project No. 80037: Investigation of surge and wave reduction by vegetation. Laboratory Publication, 1, 315.

Wu, W., Zhang, M., Ozeren, Y., Wren, D., 2012. Analysis of vegetation effect on waves using a vertical 2D RANS model. J. Coastal Res. 29(2), 383-397.

Zhan, J.M., Yu, L.H., Li, C.W., Li, Y.S., Zhou, Q., Han, Y., 2014. A 3-D model for irregular wave propagation over partly vegetated waters. Ocean Eng. 75, 138-147.

Zhang, M., Hao, Z., Zhang, Y., Wu, W., 2013. Numerical simulation of solitary and random wave propagation through vegetation based on VOF method. Acta Oceanol. Sin. 32(7), 38-46.

Zhu, L., Chen, Q., 2015. Numerical modeling of surface waves over submerged flexible vegetation, J. Eng. Mech. doi: 10.1061/(ASCE)EM.1943-7889.0000913.

Zidan, A.R., Rageh, O.S., Sarhan, T.H., El-Sharabasy, M.M., 2012. Wave Interaction with Single and Twin Pontoons. In Sixteenth International Water Technology Conference, IWTC (Vol. 16, p. 2012). 
Figure 1
Click here to download high resolution image

FIGURES
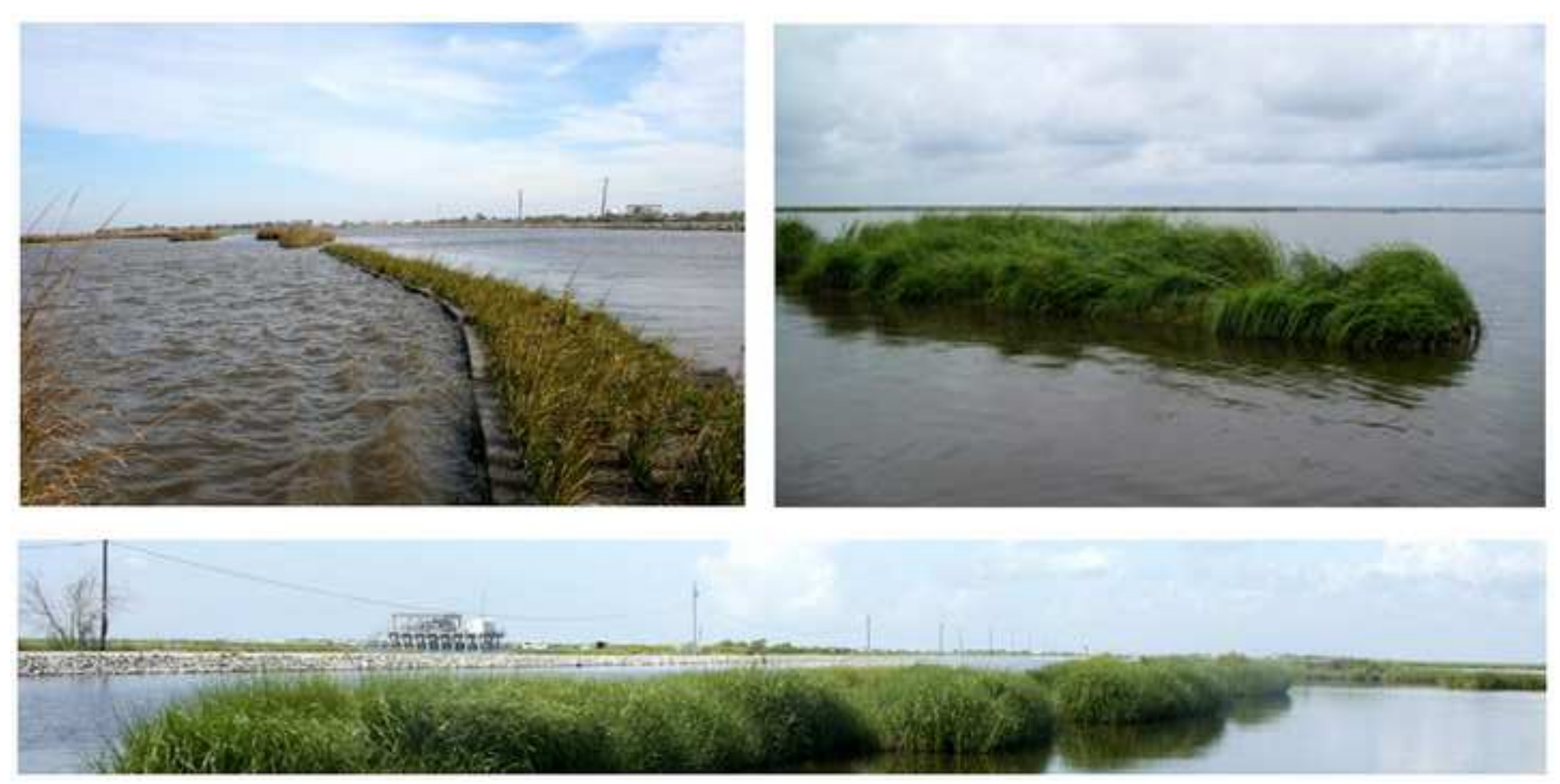


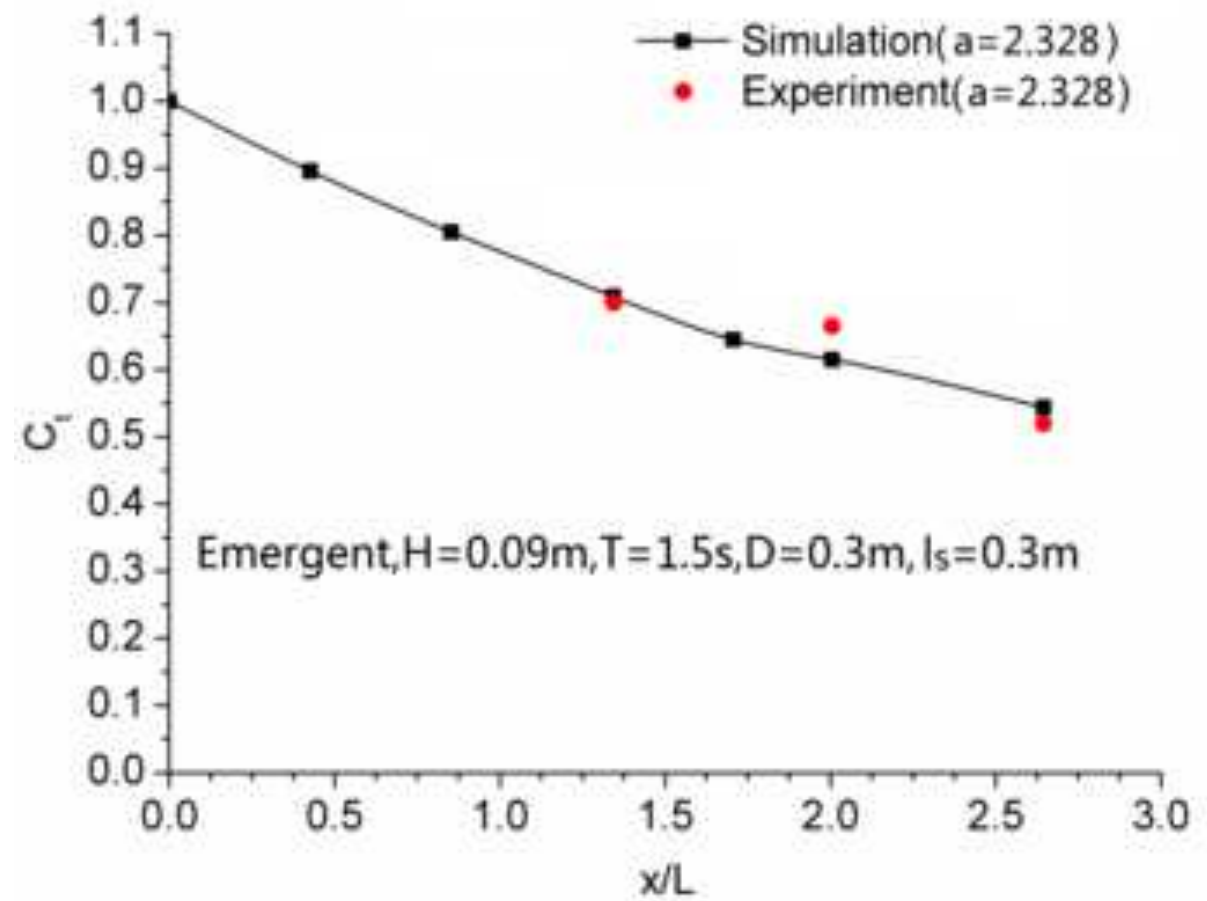

(a)

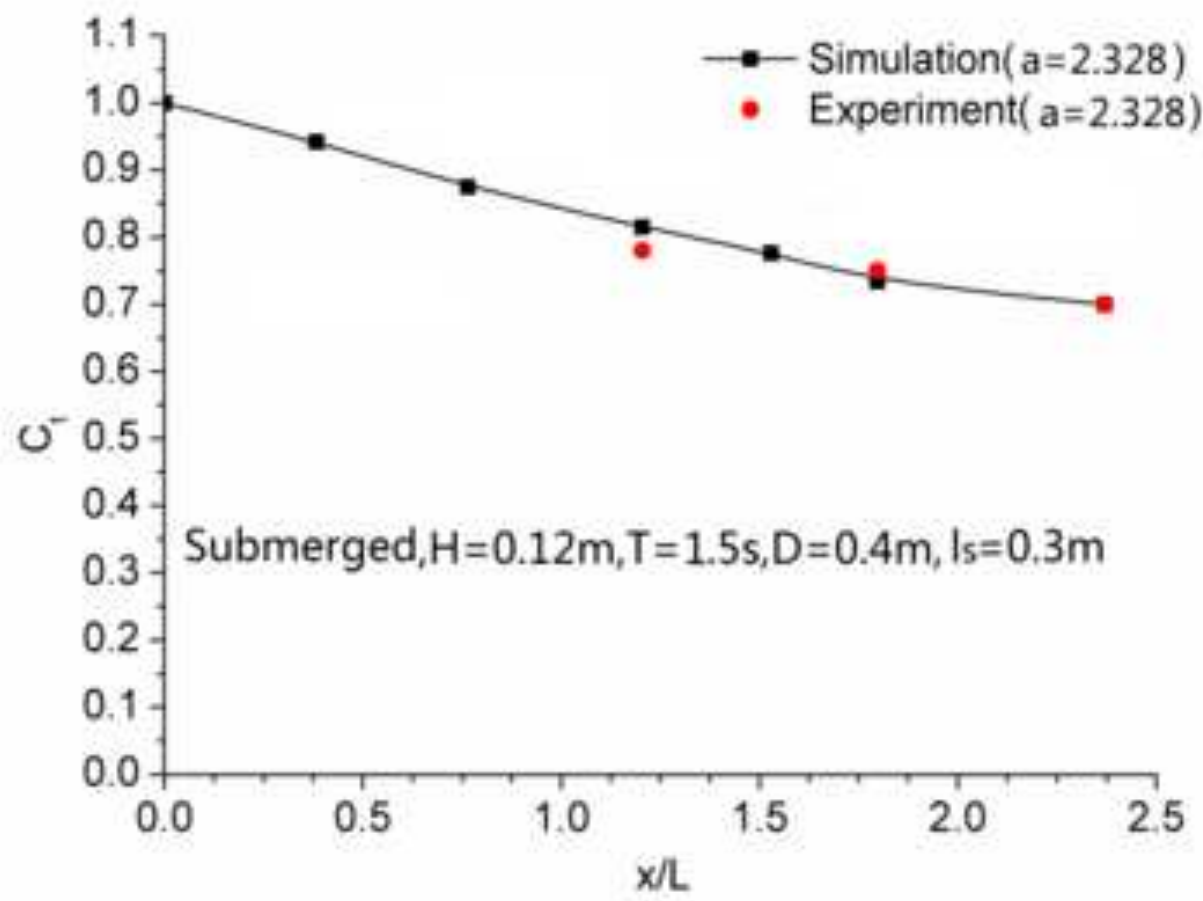

(b) 


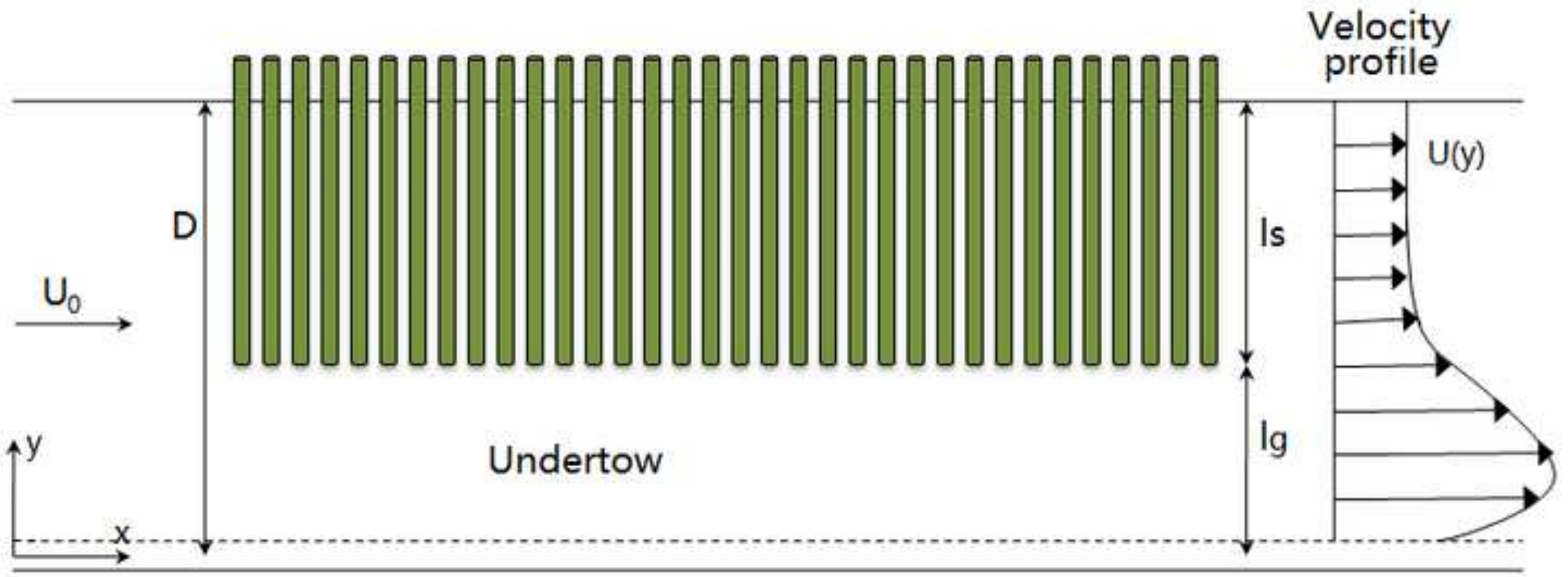


- Experiment(Plew 2010)
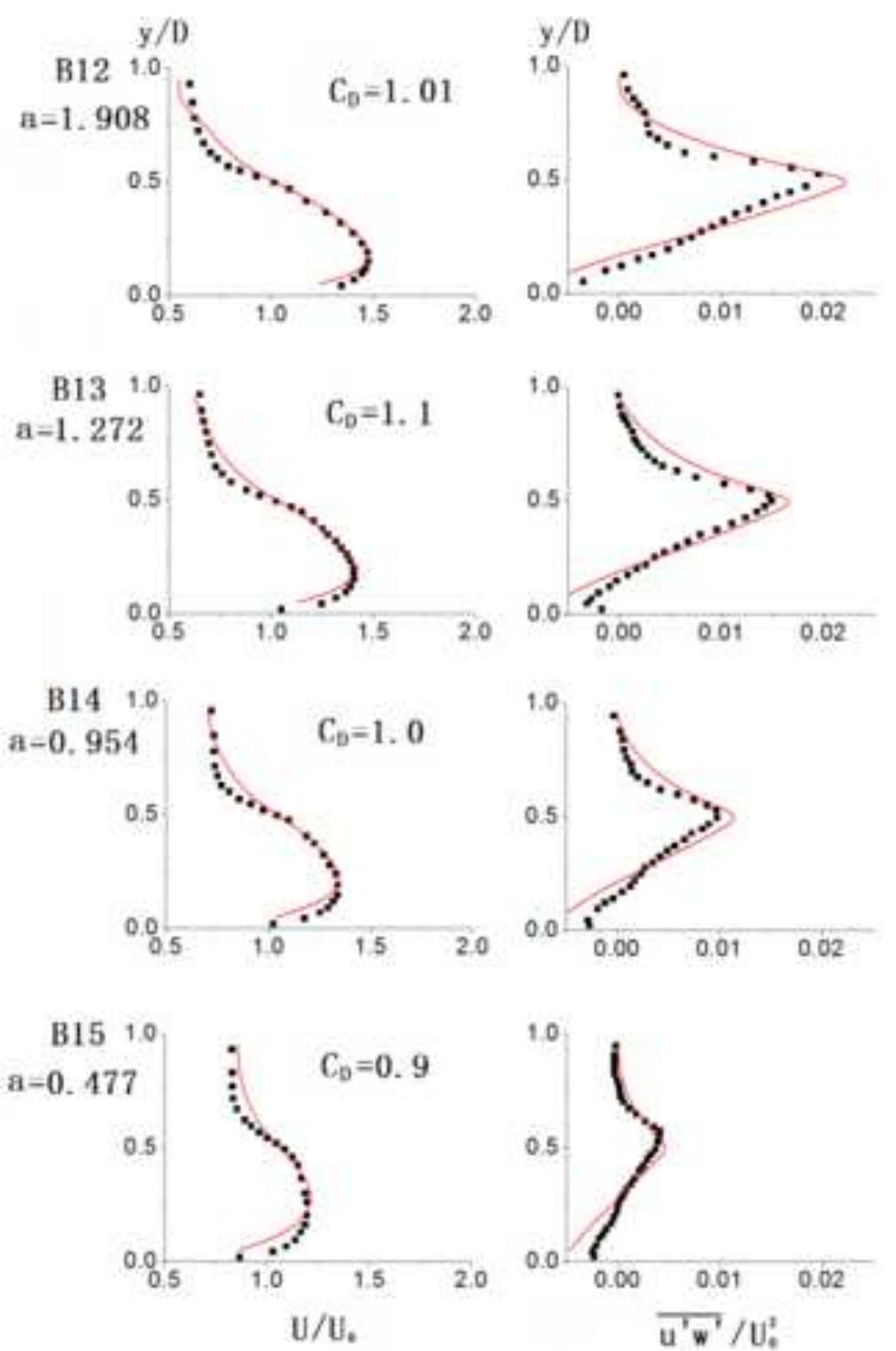

(a)

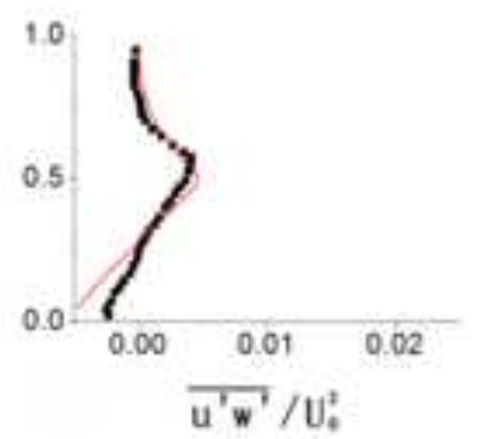

$\overline{u^{\prime} w^{\prime}} / u_{s}^{*}$
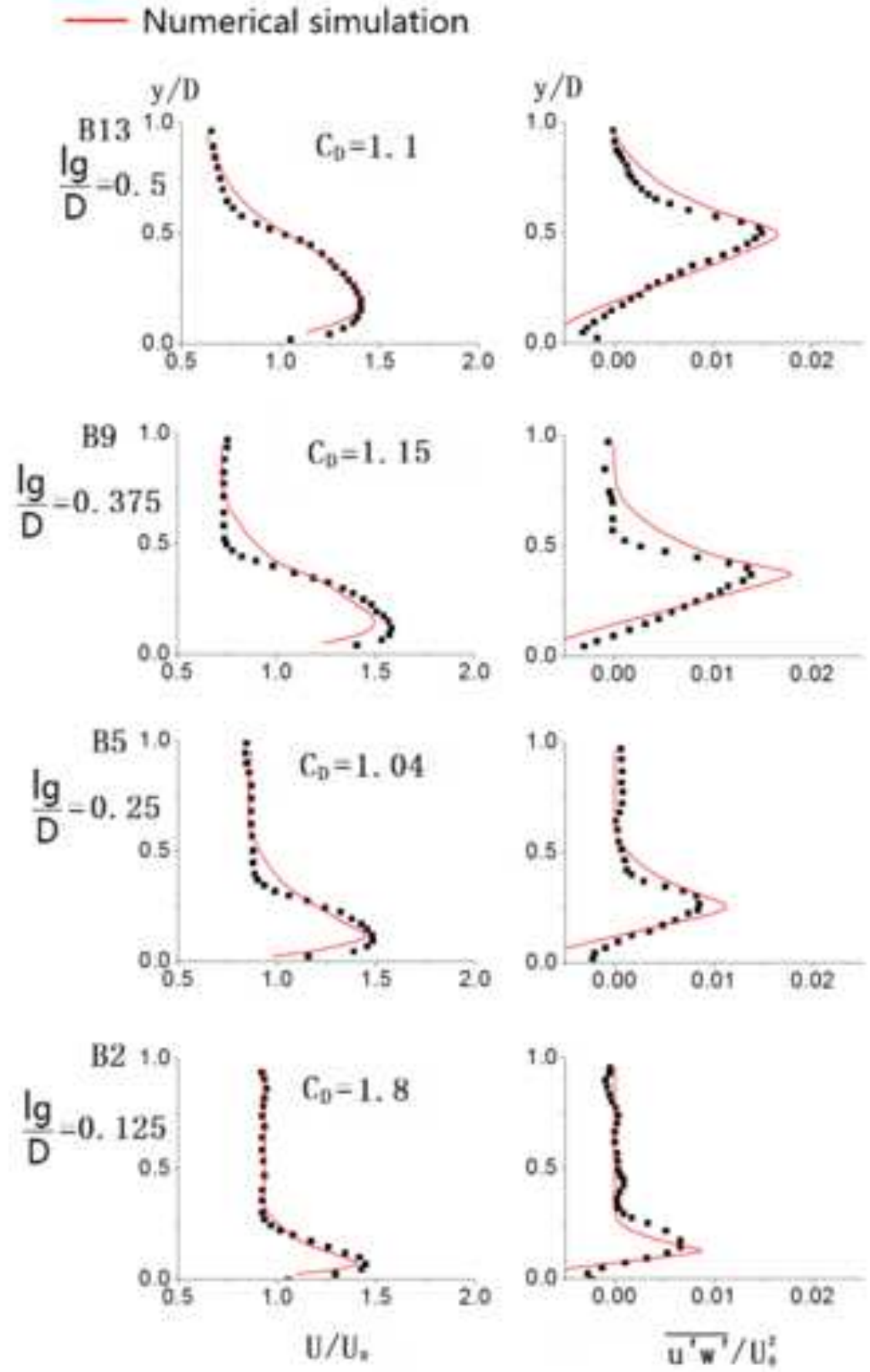

(b) 


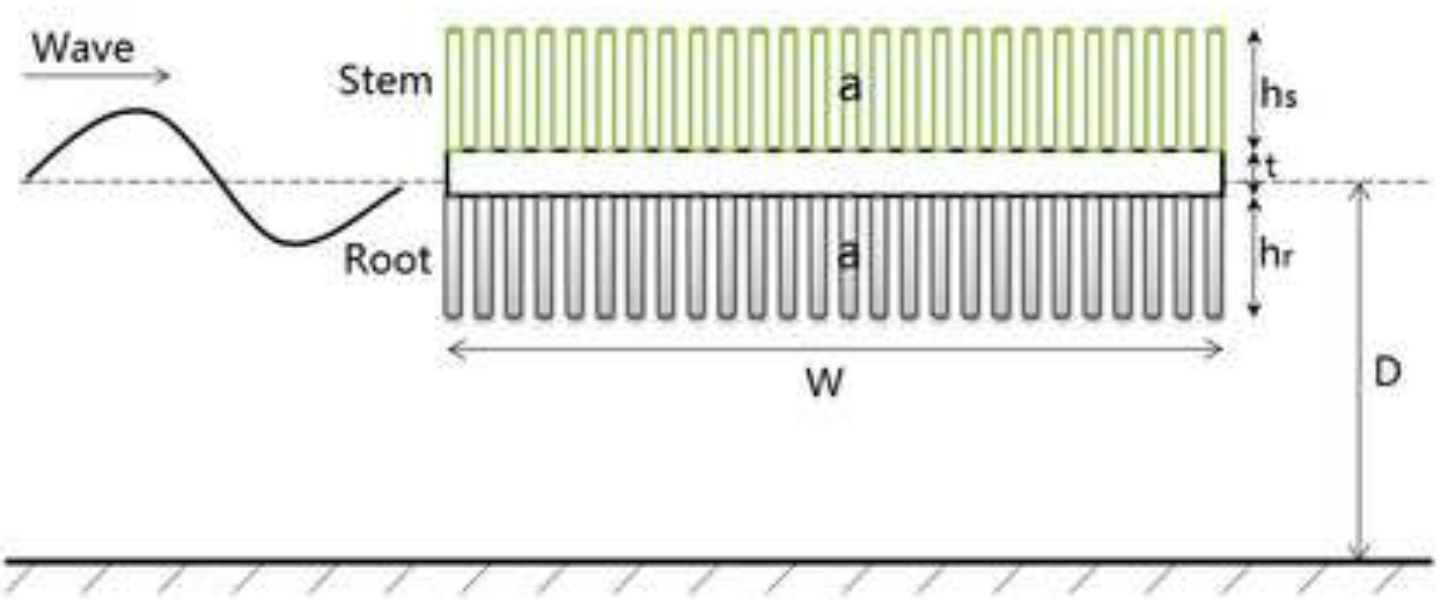

(a)

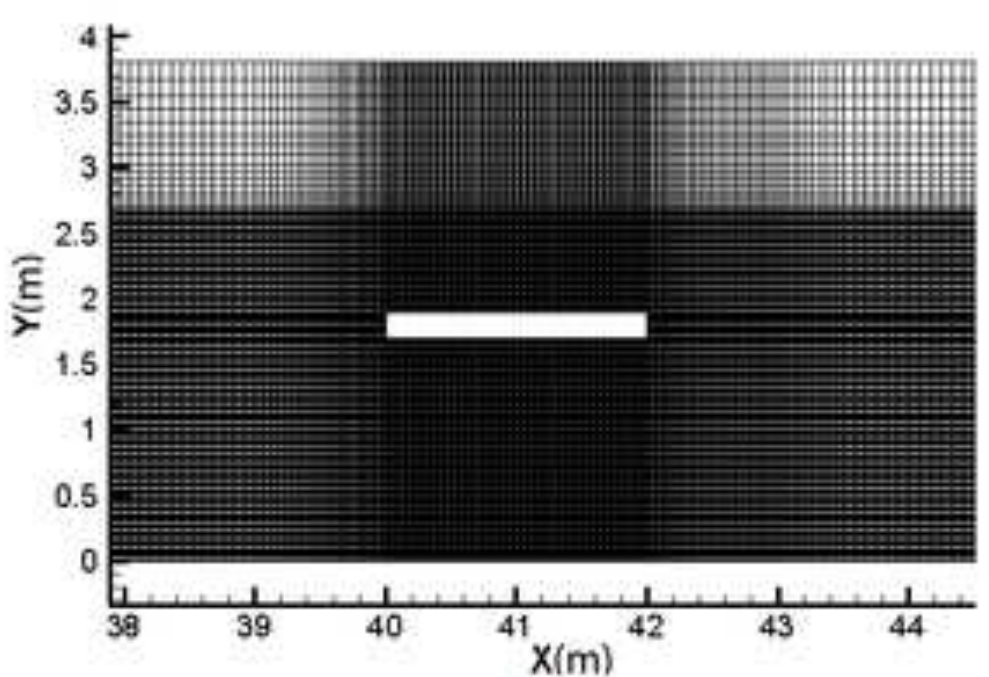

(b) 


\section{Figure 6}

Click here to download high resolution image
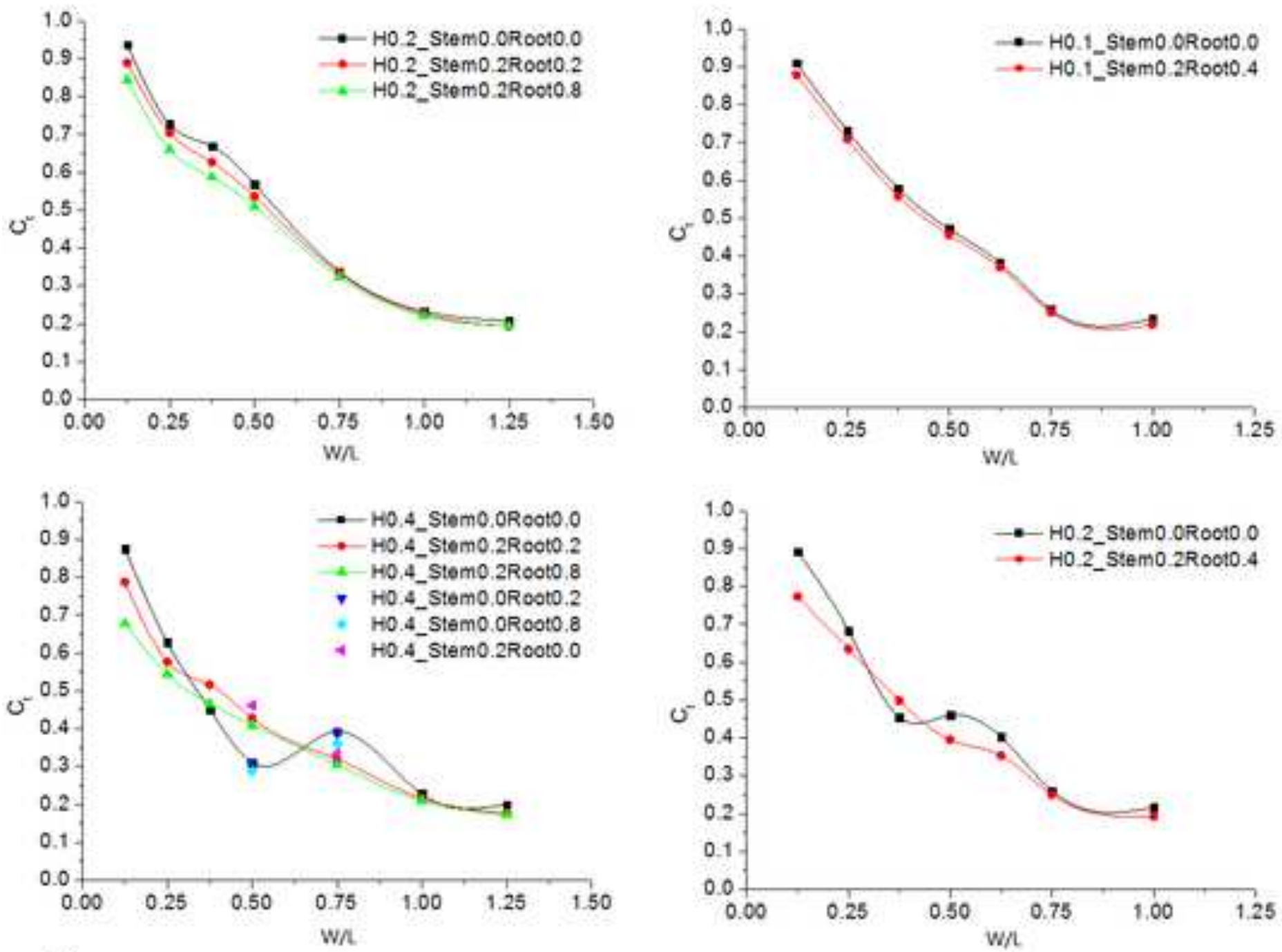

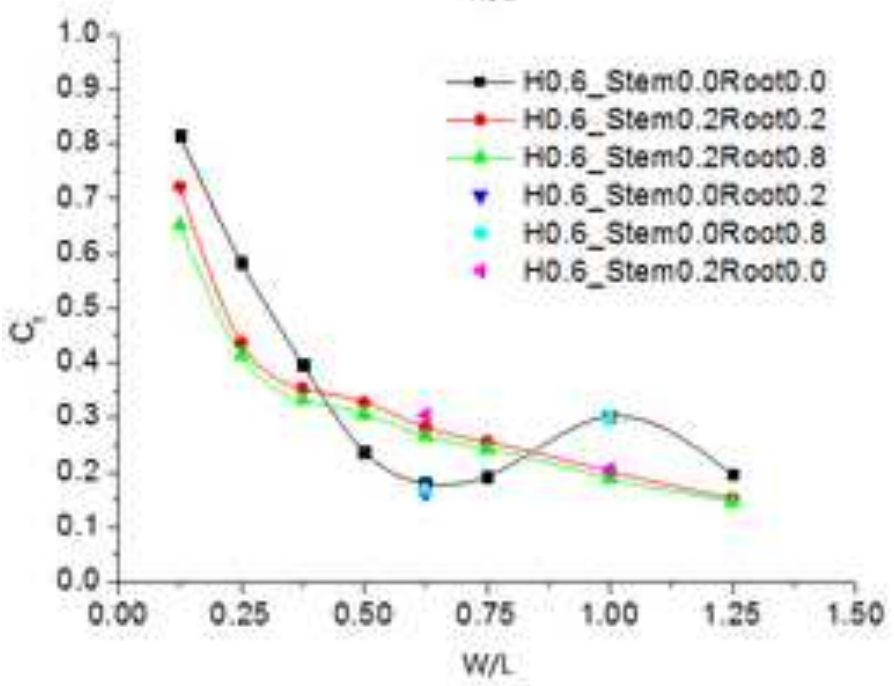

(a)

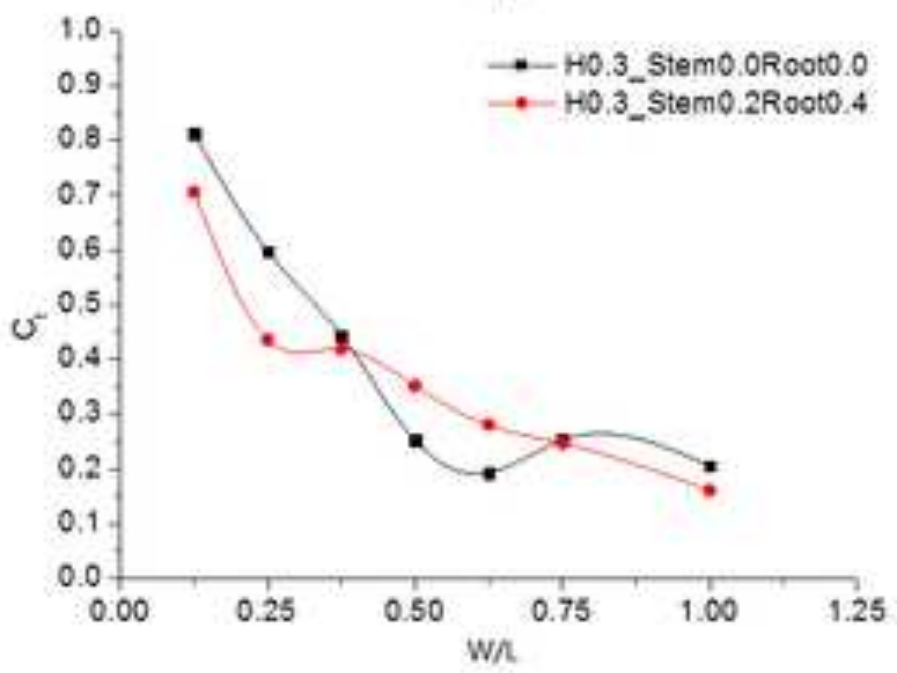

(b) 


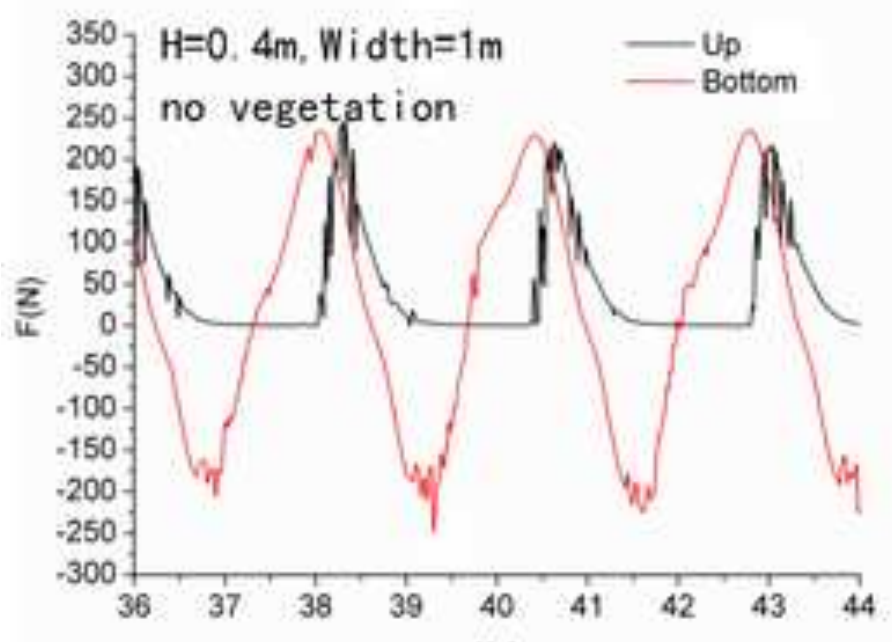

t(s)
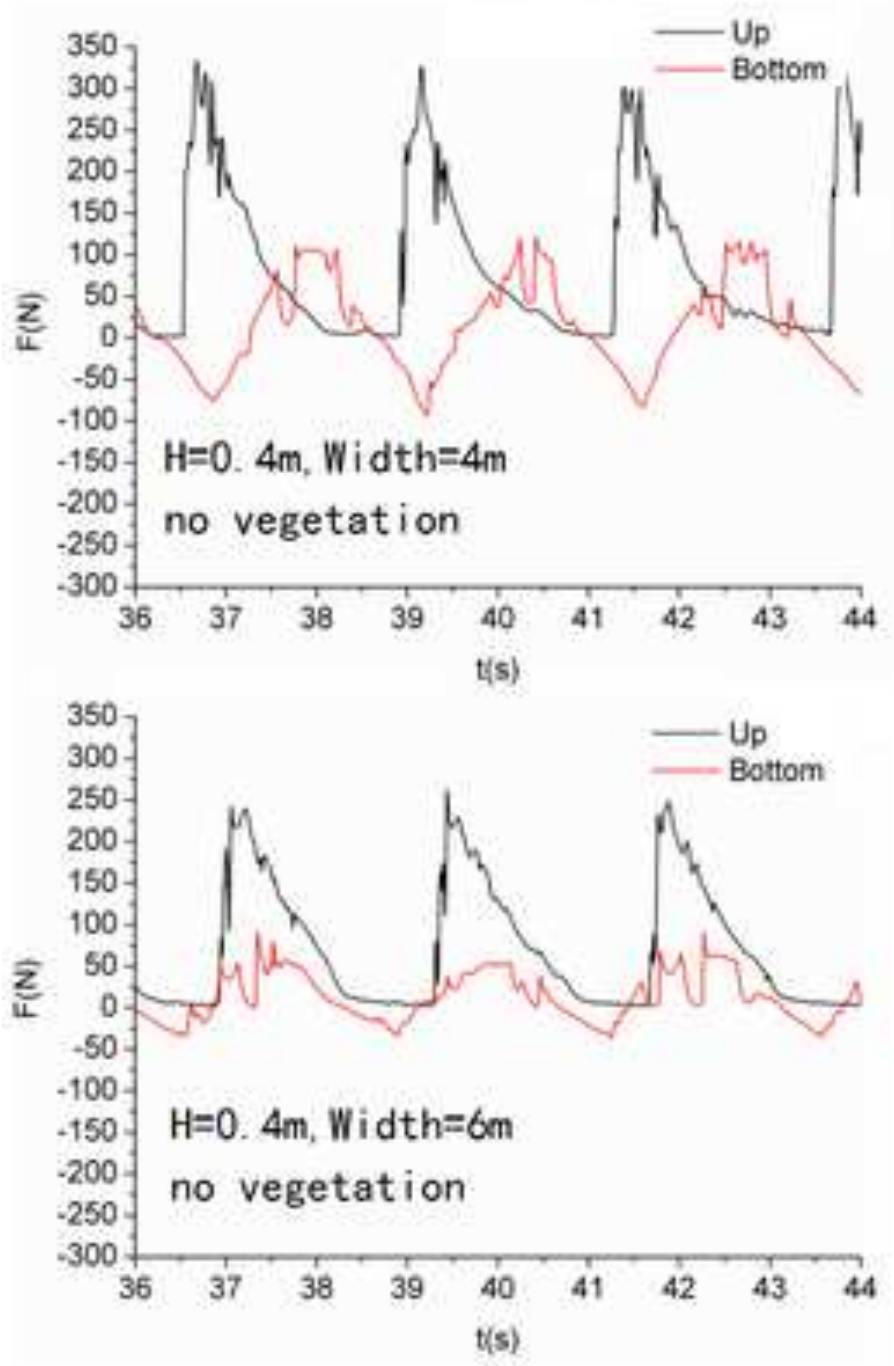

(a)
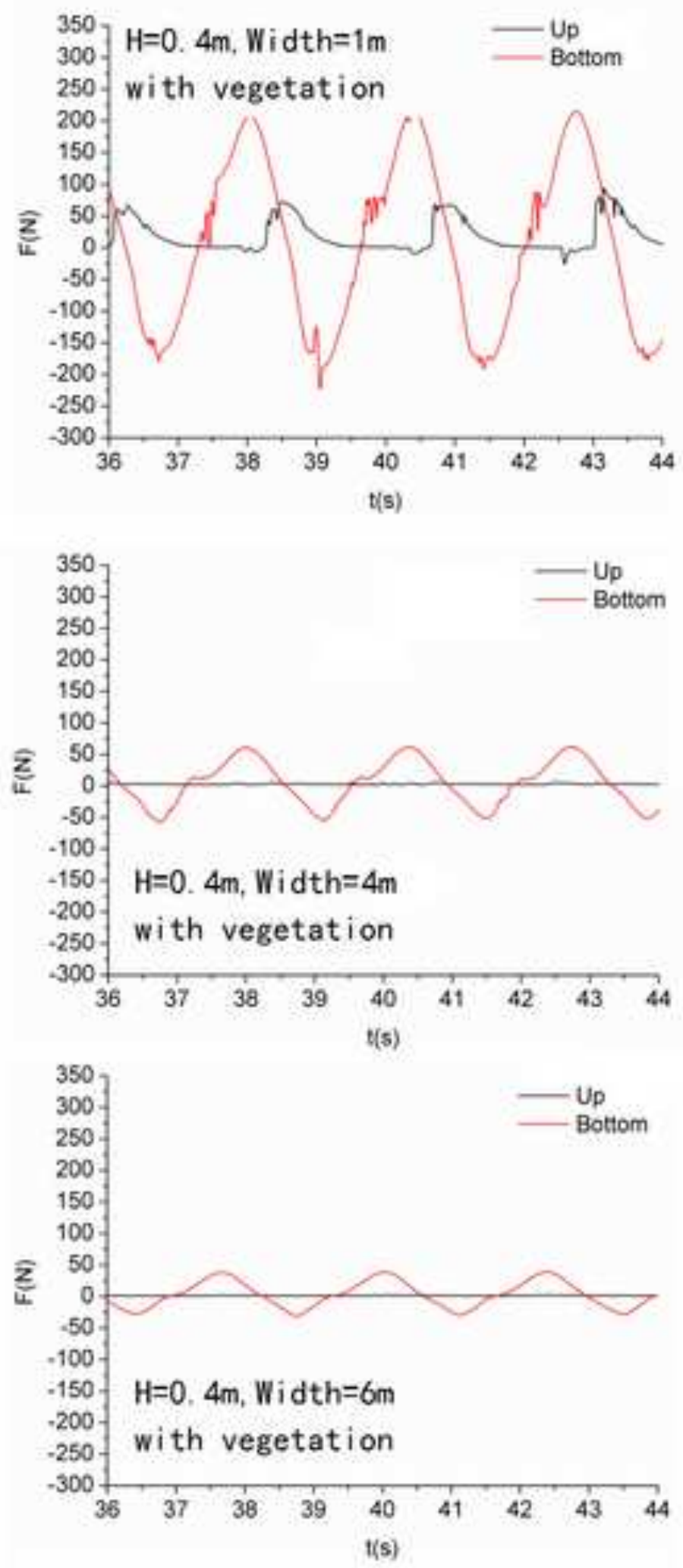

(b) 


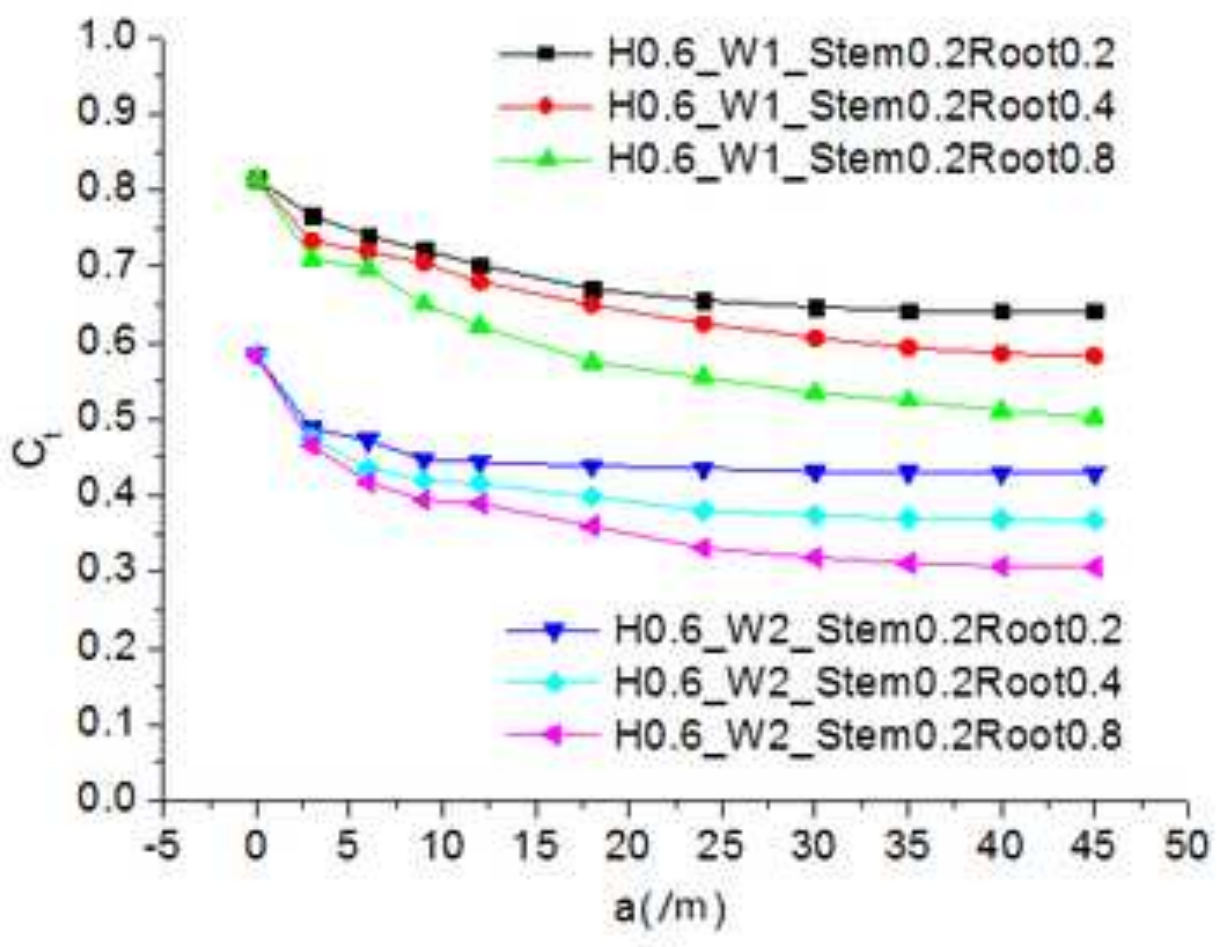

(a)

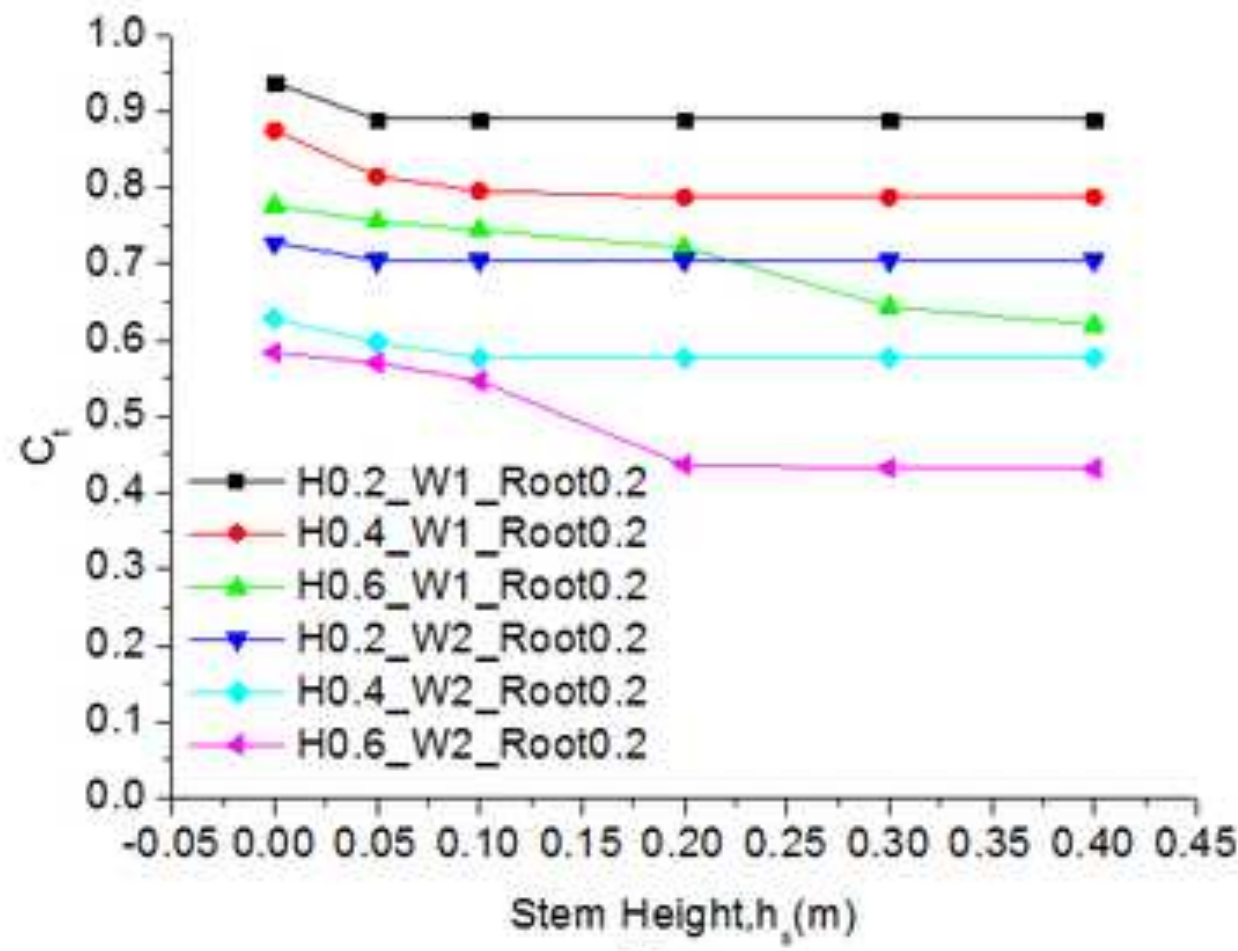

(b) 
